\title{
REDEFINICIÓN DEL CONCEPTO DEPORTE COMO PRODUCTO DE INTERCAMBIO
}

\section{REDEFINED 'SPORT' AS PRODUCT EXCHANGE}

\section{AUTOR}

Francisco Javier Ramírez Perdiguero:

Universidad Francisco de Vitoria de Madrid (España)

irperdiguero@telefonica.net

\section{RESUMEN}

En todas partes se vislumbra la evidencia del deporte como un producto de consumo muy apreciado por los ciudadanos y preciado por los empresarios. (...) El talento de muchos deportistas se desarrolla de manera meticulosa y se explota hasta alcanzar, en algunos casos, niveles increíbles, casos de los corredores automovilísticos, ciertos futbolistas o hasta alguna tenista a la que no le hace falta ni jugar (Salvador 2004, Pág. 698).

El deporte presenta diversas aristas cuando es considerado como un producto de consumo más, que satisface las necesidades y los deseos diversos de una amplia gama de consumidores.

Nuestra investigación, teniendo como sustrato la revisión de numerosas fuentes secundarias, pone de manifiesto esas diversas aristas evidenciando la relación 
existente entre todas ellas para dar lugar a un concepto único como producto, ya que su esencia integra la de un bien, un servicio y una idea.

\section{PALABRAS CLAVE}

Marketing - Deporte - Producto - Organización Deportiva - Intercambio.

\section{ABSTRACT}

Everywhere the evidence of the sport is glimpsed as a product of consumption very estimated by the citizens and boasted by the businessmen. (...) The talent of many sportsmen develops in a meticulous way and is exploited up to reaching, in some cases, incredible levels, cases of the car corridors, certain football players or up to some tennis player that it isn't necessary to play.

The sport presents diverse edges when it is considered to be a product of consumption, that it satisfies the needs and the diverse desires of a consumers' wide range.

Our investigation, taking as a substratum the review of numerous secondary sources, reveals these diverse edges demonstrating the existing relation between all of them to give place to the only concept as product, since his essence integrates that of a good, a service and an idea.

\section{KEY WORDS}

Marketing - Sports - Product - Sport Organization - Exchange. 


\section{ÍNDICE}

1. Introducción.

2. Investigación.

2.1 Grupos de discusión.

\subsection{Encuestas.}

\subsubsection{Deportistas de élite.}

2.2.2 Docentes del deporte.

2.2.3 Lideres de opinión (Expertos).

3. Resultados.

3.1 Resultados particulares sobre los jóvenes (Grupos de discusión).

3.2 Resultados particulares sobre los deportistas de élite.

3.3 Resultados particulares sobre los docentes del deporte.

3.4 Resultados particulares sobre los líderes de opinión (Expertos).

4. Conclusiones.

5. Bibliografía.

\section{Introducción}

Las personas satisfacen sus necesidades y deseos con productos. Un producto es cualquier oferta que pueda satisfacer una necesidad o un deseo (...) los principales tipos de ofertas: bienes, servicios, experiencias, acontecimientos, personas, lugares, propiedades, organizaciones, información e ideas (Kotler 2000, 11).

Este es el punto de partida, la necesidad o deseo de alguien para cuya satisfacción otro dispuso y organizó una serie de elementos aislados que, en conjunto, llamamos producto y que, ofreciendo valor y satisfacción al primero, intercambian. 
El mismo Kotler y Trias de Bes (2004) nos recuerdan que los productos en la actualidad tienen tres dimensiones: el producto principal (core product), el producto aumentado (augmented product) y el producto potencial (potencial product).

De este mismo proceso y dimensiones participa nuestro objeto de estudio, el producto deporte, en las diferentes facetas en las que se presenta ante los consumidores.

A partir de la revisión de diversas fuentes secundarias (Ramírez Perdiguero 2005) y de los resultados de nuestra investigación, deseamos integrar completamente todas las aristas de ese poliedro que denominamos deporte, en un intento holista y necesario de establecer el concepto, la representación intelectual, que nos permita un entendimiento amplio de su complejidad y de las interrelaciones que necesariamente se establecen en él, y que le convierten en algo único y excepcionalmente importante para nuestra existencia comunitaria.

No entendemos el deporte "profesional" o "alta competición" si no es en relación a la actividad de los practicantes aficionados o espectadores apasionados de ese deporte que en su infancia adquirieron el gusto por esa disciplina y que adquieren bienes relacionados con la misma, viajan, o simplemente la disfrutan en la televisión.

No entendemos el fomento del "deporte para todos" si no es en relación al paradigma "deporte profesional", que motiva a unos y equivoca a otros. Se han investigado poco las relaciones interdependientes de las distintas aristas del deporte, pero, según nuestras conclusiones, todas ellas nos parecen condiciones necesarias para la existencia del deporte en la actualidad tal como lo consumimos cada uno de nosotros.

Como bien puso de manifiesto J. S. Mill (1927), siempre ha existido una fuerte tendencia a creer que todo aquello que tiene un nombre debe ser una entidad 
existencial, debe tener una existencia independiente y en sí. Y cuando no existe una entidad real que responda al nombre, los hombres no por esta razón suponen que no existe, sino que imaginan que es algo especialmente abstruso y misterioso.

Algo así sucede, si se nos permite, con la entidad que responde al nombre "deporte", su esencia es especialmente compleja y misteriosa en la actualidad, fruto de un sistema que lo produce en diversas formas.

Paredes Ortiz (2002) aborda el concepto deporte desde la definición del término, cronológicamente, en los distintos Diccionarios de la Lengua Española del los siglos XIX y XX y las definiciones de los autores que se consideran autoridades clásicas en materia deportiva: Coubertin (1949), Guillemain (1955), Di Scala (1956), Seurin (1956), Diem (1956), Guillet (1971)Tindall(1976), Karag (1959), Mclntosh (1983), Antonelli y Salvini (1984), Cagigal (1966, 1981), Anshel y Col (1991), Shepard (1994), García Ferrando (1990, 1998), Piernavieja (1996), entre otros muchos de una lista interminable.

Es obvio, que la perspectiva lingüística es insuficiente para entender la naturaleza del deporte como producto contemporáneo sujeto a múltiples relaciones de intercambio.

We all know what sport is afirman Westerbeek y Smith $(2003,52)$, tan rotunda como ingenuamente, porque ya nos dirán si tiene que ver lo que "deporte" significa para un empresario (Florentino Pérez, Presidente del Real Madrid, y su equipo de gestión), un concejal municipal, el Consejero de una Comunidad Autónoma o la mismísima Ministra de Educación y Cultura, un representante (coacher), un periodista deportivo en prácticas en una cadena autonómica de TV,... con lo que significa "deporte" para un sedentario espectador, un activo practicante en busca de un cuerpo poderoso, un niño que emula a su estrella con auténtica idolatría, un especialista en medicina deportiva... o lo que significa para la mayoría de los deportistas profesionales de elite. ¿Hablamos todos de lo mismo? La respuesta es no, 
aunque millones de "clientes" del deporte en el mundo lo entiendan de la misma forma genérica como producto de consumo. Jugar al fútbol es una actividad que se realiza de forma exactamente igual en cualquier punto del planeta y ver un partido de voley-playa, también.

Esta preocupación por determinar y examinar las circunstancias del deporte viene siendo tarea prioritaria de distintas instancias en el seno de la Unión Europea desde que, en 1975, en la Primera Conferencia de Ministros responsables del deporte, se elaborara la Carta Europea del Deporte cuyos ocho artículos recogen las apreciaciones, características y recomendaciones que debe proteger el derecho proclamado a favor de tos las personas.

Así en los distintos foros y cumbres, Declaración de Amsterdam, 1997; Consejo Europeo de Viena, 1998; Consejo Europeo de Helsinki, 1999; Declaración de Niza, 2000; Proyecto de Constitución Europea, 2004, el deporte ha sido objeto de profundos debates y análisis cuya finalidad es definir lo que el deporte debe significar en la convivencia de la Unión Europea más allá de la moneda y otras políticas comunes.

Salvador (2004), en El Deporte en Occidente. Historia, Cultura y Política, es a nuestro juicio quien mejor a compendiado y revisado el camino del deporte desde sus primeras manifestaciones hasta nuestros días. Basándose en una extensísima bibliografía entre los que se encuentra los trabajos de los clásicos Bickel (1944), Mclntosh (1963), Diem (1966), Mandell (1966), Ortega (1967), Ulmann (1967), Huizinga (1972), (Kirk 1985), Gadamer (1995), Sennett (1997), Gadamer (1995), etc. que han tratado el deporte en el sentido que interesa a nuestra investigación.

Coincidimos con Salvador (2004) en que es a partir de los años 20 del siglo XX, cuando el deporte se convierte en un fenómeno planetario donde USA es el país 
dominante, creemos que por el momento, ya que China, en Beijing 2008, nos aventuramos a asegurar, tomará el liderazgo global del deporte.

Nuestro punto de partida es el individuo, el "cliente" para quien el deporte es un producto (poliédrico), como no podría ser de otra manera en el contexto de marketing de este trabajo de investigación, entendiendo por producto todo bien, servicio o idea susceptible de intercambio, que participa de esas tres naturalezas esenciales como hecho singular y poco común en otros productos. Precisamente su complejidad estriba en esto, a veces se presenta como un bien en sí mismo o derivado de un hecho deportivo, las camisetas vendidas masivamente tras el fichaje de una megaestrella como Beckham, actividad que denominamos merchandising, 0 la motivación de la práctica deportiva traducida a salud de la población; otras veces, se trata de una idea política, por ejemplo la candidatura de Madrid 2012 y su mayor o menor pujanza en función del programa político en las Elecciones Municipales de cada partido, o de salud; y de forma fundamental para el entramado deportivo, se trata también de un servicio, por ejemplo ocio y entretenimiento, que nos proponen las diferentes cadenas de televisión portadoras de los derechos de emisión de los eventos deportivos más importantes y que determinan el éxito y son elemento fundamental de su parrilla de programación, Champions League, Mundiales de diversas disciplinas deportivas, Tour de Francia, Grand Slams, por ejemplo. Todo ello queda recogido en un mismo término: deporte. 


\section{Investigación}

Nuestro trabajo incluye dos tipos de técnicas aplicadas a cuatro segmentos diferentes de sujetos:

\subsection{Grupos de discusión}

Para la utilización de grupos de discusión (focus group) en nuestra investigación, determinamos el número de grupos requeridos, en este caso cuatro grupos. Ya se tenía información recopilada sobre el objeto de estudio y se habían generado hipótesis acerca del tema, considerando los factores o variables que intervienen.

La composición de los grupos de discusión, jóvenes universitarios de ambos sexos, entre 18 y 22 años, por ser los más afines a la práctica deportiva (Ga Ferrando 2000). Las sesiones de trabajo tuvieron entre hora y media y dos horas de duración. Cada grupo estuvo integrado por ocho participantes, con un equilibrio entre mujeres y hombres, dimensión aceptada para esta técnica que tradicionalmente propone entre ocho y diez personas, aunque se presenta la tendencia a disminuir la cifra hasta cinco personas. En cuanto a la disposición de los participantes, se propició un ambiente privado, sin interrupciones ni ruidos, con un ambiente "neutro" y una instalación que contribuía a que no se sintieran inhibidos.

Se preparó una lista de temas o cuestiones que respondían a los objetivos de la investigación y que fueron tratados por los jóvenes participantes. Entre ellos la relación de intercambio con el deporte, la relación deporte-Internet, factores clave del deporte, significados como concepto y como objeto del marketing, entorno global deportivo, modelo deportivo para la Unión Europea, entre otros aspectos que consideramos de interés como los intereses deportivos de los jóvenes, su 
caracterización de la relación de intercambio, aspiraciones sobre el deporte en Internet y su posible demanda.

\subsection{Encuestas}

Para desarrollar este método se utilizaron ambas formas: el cuestionario, como técnica que se emplea para obtener información a escala masiva y que puede aplicarse al universo o a una muestra, utilizando para ello un cuestionario impreso que las personas responden por si mismas; y la entrevista, en este caso, estandarizada o estructurada, orientada hacia la búsqueda de información más explicativa e interpretativa acerca de los elementos objeto de estudio y además con el propósito de profundizar y comprender mejor la información recopilada.

\subsubsection{Deportistas de elite}

En esta investigación se aplicaron cuestionarios a deportistas de elite y a docentes vinculados con el ámbito deportivo y también entrevistas a expertos del deporte, que son líderes de opinión en este medio.

En el caso que nos ocupa, se aplicaron 140 cuestionarios a deportistas de elite, con la intención de conocer y cuantificar sus opiniones con relación a los rasgos vinculados al deporte como producto así como el nivel de importancia inclusive con una óptica de futuro; elementos que pueden hacer del deporte un producto susceptible de intercambio y que puedan ser utilizados en marketing así como otros factores de interés para el producto deporte en un mercado global, fundamentalmente para no desaprovechar la oportunidad de consultar a estos deportistas que constituyen un grupo representativo del conjunto del deporte español que con más intensidad vive la práctica deportiva, y que abrirían el camino a otras investigaciones. 


\subsubsection{Docentes del deporte}

Se encuestaron 200 docentes vinculados al ámbito deportivo, procedentes de:

- Bilbao (46\%)

- Madrid (26\%)

- Valencia (24\%)

- Barcelona (1\%)

- Zaragoza (1\%)

- Burgos (1\%)

- Orense (1\%)

Las variables analizadas fueron: materia impartida, sexo, edad y tipo de centro.

La variable Materia impartida fue recodificada de la siguiente manera:

- $\mathbf{1}$ = Enseñanza Formativa compuesta por: Reglamentación deportiva, Didáctica, Audiovisual, Planes de entrenamiento, Salud y Deporte, Resp. Deportes, Asesor deportivo, Asesor técnico, Gestor deportivo, Técnico deportivo. Monitor.

- $\mathbf{2}$ = Educación Física compuesta por: Educación Física.

- $\mathbf{3}$ = Enseñanza Práctica compuesta por: Tenis, Padel, Natación, Musculación, Aeróbic, Baloncesto, Gimnasia, Iniciación Deportiva, Aprendizaje Motor, Fútbol, Fitnes, Motociclismo, Deporte Profesional, Actividad Física, Coordinador, Entrenamiento, Sicomotor.

- 4 = Comercial formado por: Marketing, Publicidad, Dirección Estratégica, Gestión, Finanzas, Fundamentos Marketing, Lenguaje Publicitario, Estructura y Organización, Instalaciones, Dirección Comercial, Publicidad para Empresas. 
- 5 = Otras enseñanzas compuesto por: Salud y deporte, Contacto Ayuntamientos, Médico, Responsable actividad extraescolar de deporte, Técnico deporte ayuntamiento, Act. Relacionadas con la salud, Deportes, Concejalía de deportes.

Edad de los docentes ha sido recodificada de la siguiente manera:

$$
1<=30 \text { años }
$$

231 - 45 años

\section{$3>45$ años}

Tipo de Centro ha sido recodificada de la siguiente manera:

$$
\begin{aligned}
& 1=\text { Universidad } \\
& 2=\text { Educ. Secundaria } \\
& 3 \text { = Educ. Primaria } \\
& 4=\text { Otros centros }
\end{aligned}
$$

Se obtuvo información sobre los rasgos vinculados al deporte como producto así como su nivel de importancia y primacía futura; los valores del deporte auténticamente educativos para los jóvenes; tendencias ulteriores del deporte; utilización de las herramientas del marketing en el deporte, entre otros indicadores útiles e importantes para futuras investigaciones.

\subsubsection{Líderes de opinión (Expertos)}

En nuestra investigación hemos entrevistado a expertos, que sin duda son líderes de opinión en su ámbito de responsabilidad, en el momento de la investigación. Se realizaron 34 entrevistas de cuyas respuestas realizamos un análisis de contenido, teniendo en cuenta tanto los elementos disímiles como los similares del contenido de los argumentos expuestos, así como la interconexión entre las diferentes preguntas y el tipo de entrevistado. La guía de entrevista se envió por correo electrónico a 90 
sujetos seleccionados y se recibieron 29 respuestas por la misma vía y cinco por correo.

En la entrevista estandarizada o estructurada utilizada se abordaron elementos sobre el tema objeto de estudio, entre ellos los factores clave del deporte; las tendencias en cuanto a la previsión del futuro desarrollo de los mismos; la importancia de Internet para la relación de intercambio en el deporte; el posicionamiento de Internet con relación a otros medios; el mercado global del deporte; la importancia y posibilidad de la utilización del marketing en el deporte y sobre el modelo deportivo actual de la Unión Europea. Para explotar al máximo esta oportunidad de acceder a destacadas personalidades del marketing y el deporte, además indagamos sobre aspectos importantes y convenientes para posteriores investigaciones, aunque no constituyan objetivos en sí mismos de este trabajo.

\section{Resultados}

\subsection{Resultados particulares sobre los jóvenes (Grupos de discusión)}

Después de realizar un análisis del contenido de las transcripciones de cada uno de los grupos de discusión, en concordancia con las asociaciones que realizan, y destacando las ideas principales de cada uno de ellos, se concluye que los rasgos característicos coincidentes en los cuatro grupos de jóvenes son los siguientes:

- Los individuos, en su discurso, evidencian la polivalencia esencial del deporte asociándolo a las diversas funciones que le reconocen y que lo caracterizan como producto complejo, con el cual se relacionan de formas diversas: practicándolo, siguiéndolo a través de los medios, individualmente o con los amigos. 
- En todos los grupos se percibe un gusto general por el deporte, que se concibe desde dos dimensiones claramente diferenciadas:

- La dimensión profesional, principalmente como espectáculo, donde el consumo está muy condicionado por los mass media, el marketing y la publicidad.

Al deporte lo impulsan los medios de comunicación.

Potencian la retransmisión de aquellas modalidades que mayores beneficios económicos proporcionan. En este entorno destacan factores como el espectáculo, negocio, emoción, competitividad, agresividad, fanatismo, odio, actividad física, racismo, compañerismo, ayuda, apoyo, y trabajo en equipo.

El deporte, en esta dimensión, se puede consumir de modo pasivo, a través de los mass media, o de modo activo, acudiendo a espectáculos deportivos, adquiriendo merchandising y otros productos relacionados, consultando contenidos medios y, en menor medida, practicándolo profesionalmente.

- La dimensión lúdica, como forma de hacer ejercicio, donde la práctica de cualquier modalidad, ya sea individualmente 0 con amigos, proporciona valiosas recompensas como la satisfacción, esfuerzo, superación personal, diversión, amistad, salud, relaciones sociales, por ejemplo.

- Los factores que componen su concepto son múltiples y van y vienen desde las dos dimensiones sin orden, jerarquía, ni distinción. Todo ello en su conjunto constituye su concepto, que está integrado por diversas aristas: educativa, salud, económica, social, cultural y lúdica, fundamentalmente. No todos los factores expresados son positivos, también afloran aspectos negativos, como el doping, fanatismo, rivalidad extrema, violencia, y entorno machista.

Es destacable que, cuando el deporte está muy interiorizado, la pasión es el sentimiento dominante. 


\begin{tabular}{|c|c|c|c|c|c|c|}
\hline \multicolumn{7}{|c|}{ Asociaciones al término "DEPORTE" } \\
\hline & EMOCIONALES & VALORES & SOCIOECONÓMICOS & \begin{tabular}{|l|} 
CULTURAL- \\
HISTÓRICOS
\end{tabular} & $\begin{array}{l}\text { ICÓNICO- } \\
\text { SIMBÓLICOS }\end{array}$ & OTROS \\
\hline GRUPO 1 & \begin{tabular}{|l|} 
Buen ambiente \\
Fanatismo \\
Odios inútiles \\
Risas \\
Desahogo \\
\end{tabular} & $\begin{array}{l}\text { Amigos } \\
\text { Compañerismo } \\
\text { Ejercicio } \\
\text { Cuerpazo }\end{array}$ & $\begin{array}{l}\text { Negocio } \\
\text { Entretenimiento } \\
\text { Ruedas de prensa }\end{array}$ & $\begin{array}{l}\text { Juego } \\
\text { Competición } \\
\text { Seguimiento } \\
\text { Gritos }\end{array}$ & $\begin{array}{l}\text { Reunión } \\
\text { Sudor } \\
\text { Ídolos } \\
\text { Vestuarios }\end{array}$ & \\
\hline GRUPO 2 & $\begin{array}{l}\text { Fanatismo } \\
\text { Satisfacción } \\
\text { Decepción / Alegría } \\
\text { Euforia }\end{array}$ & $\begin{array}{l}\text { Concentración } \\
\text { Salud } \\
\text { Tiempo } \\
\text { Esfuerzo } \\
\text { Discriminación } \\
\text { Superación } \\
\text { Narcisismo } \\
\text { Fraternidad }\end{array}$ & $\begin{array}{l}\text { Dinero } \\
\text { Recompensa } \\
\text { Manipulación }\end{array}$ & $\begin{array}{l}\text { Competición } \\
\text { Contacto } \\
\text { Competitividad } \\
\text { Equipo }\end{array}$ & $\begin{array}{l}\text { Balón } \\
\text { Raqueta } \\
\text { Maza } \\
\text { Nazismo } \\
\text { Tiempo }\end{array}$ & \\
\hline GRUPO 3 & \begin{tabular}{|l} 
Pasión \\
Adrenalina \\
Sufrimiento \\
¿Necesidad? \\
Autoestima \\
Nerviosismo \\
Emoción \\
Fanatismo \\
Sentimiento \\
Violencia \\
Gozo
\end{tabular} & $\begin{array}{l}\text { Superación } \\
\text { Disciplina } \\
\text { Trabajo en } \\
\text { equipo } \\
\text { Compañerismo } \\
\text { Esfuerzo } \\
\text { Sacrificio } \\
\text { Formación/ } \\
\text { Educación } \\
\text { Valores } \\
\text { Orgullo } \\
\text { Respeto } \\
\text { Salud } \\
\text { Ejercicio } \\
\text { Insulto }\end{array}$ & $\begin{array}{l}\text { Espectáculo } \\
\text { Diversión } \\
\text { Entretenimiento } \\
\text { Negocio } \\
\text { Masas }\end{array}$ & $\begin{array}{l}\text { Competición } \\
\text { Rivalidad } \\
\text { Sociedad } \\
\text { Cultura } \\
\text { Equipos } \\
\text { Nacionalismos } \\
\text { Historia } \\
\text { Tradición } \\
\text { Afición }\end{array}$ & $\begin{array}{l}\text { Colores } \\
\text { Ídolos }\end{array}$ & $\begin{array}{l}\text { Diferencia de } \\
\text { personalidad } \\
\text { Machismo } \\
\text { Feminismo }\end{array}$ \\
\hline GRUPO 4 & $\begin{array}{l}\text { Emoción } \\
\text { Sufrimiento } \\
\text { Satisfacción } \\
\text { Ilusión } \\
\text { Alegría } \\
\text { Riesgo de vida } \\
\text { ¿Diversión? } \\
\text { Fanatismo }\end{array}$ & $\begin{array}{l}\text { Salud / } \\
\text { Mantenimiento f. } \\
\text { Actividad Física } \\
\text { Fuerza de } \\
\text { voluntad } \\
\text { Trabajo } \\
\text { Sacrificio } \\
\text { Educación } \\
\text { Trabajo en } \\
\text { equipo } \\
\text { Amistad } \\
\text { Libertad } \\
\text { Unión } \\
\text { Dopaje } \\
\text { Superación } \\
\text { Frialdad } \\
\text { Renuncia }\end{array}$ & $\begin{array}{l}\text { Espectáculo } \\
\text { ¿Diversión? } \\
\text { Ocio } \\
\text { Negocio } \\
\text { Entretenimiento }\end{array}$ & $\begin{array}{l}\text { Forma de vida } \\
\text { Ocio } \\
\text { Normas } \\
\text { Competitividad } \\
\text { (Rivalidad) }\end{array}$ & Victoria & $\begin{array}{l}\text { Cansancio } \\
\text { Coordinación }\end{array}$ \\
\hline
\end{tabular}

Tabla 1. Asociaciones al término 
REVISTA DE LA SEECI.

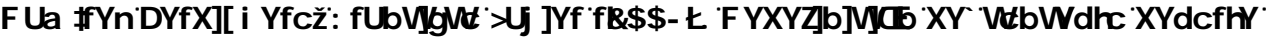

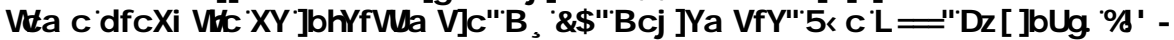

, 661 س

\begin{tabular}{|c|c|c|c|c|}
\hline & GRUPO 1 & GRUPO 2 & GRUPO 3 & GRUPO 4 \\
\hline EMOCIONALES & $\begin{array}{l}\text { Un balón entrando en la portería } \\
\text { Un atleta llorando (decepción) } \\
\text { El dolor, un pié que se ha roto } \\
\text { El sol } \\
\text { Complicidad con los amigos } \\
\text { cuando juegas } \\
\text { Niños pequeños } \\
\text { La emoción de los padres } \\
\text { Los Simpson: Lisa y Bart } \\
\text { peleando al hockey } \\
\text { La expectación del resultado } \\
\text { El triunfo: en atletismo un sprint } \\
\text { final (Música de Carros de fuego } \\
\text { y Queen) }\end{array}$ & $\begin{array}{l}\text { Niños felices jugando } \\
\text { Cuando alguien gana una } \\
\text { carrera, sudoroso y sonriente y } \\
\text { con la cara machacada } \\
\text { Un señor trajeado que cuando } \\
\text { va al estadio se cambia de } \\
\text { ropa y se pone a gritar, a } \\
\text { "descolgarse" } \\
\text { Niños saltando a la comba } \\
\text { Jordan volando a canasta } \\
\text { Las hermanas Williams } \\
\text { jugando una final } \\
\text { Indigente deportista que no } \\
\text { vende su medalla } \\
\text { Barrichello pasando a } \\
\text { Schumaher }\end{array}$ & $\begin{array}{l}\text { Sillón+amigos+cervezas } \\
\text { El deporte es como una vida } \\
\text { Una cascada de agua, por la } \\
\text { fuerza, por la emoción } \\
\text { Silencio cuando marca el gol el } \\
\text { equipo contrario } \\
\text { Un caballo a punto de saltar } \\
\text { sabiendo que todo el mundo te } \\
\text { mira } \\
\text { La celebración en las fuentes } \\
\text { Llanto de un aficionado con la } \\
\text { cara pintada } \\
\text { Velocidad, todo blanco } \\
\text { El ruido estruendoso de la F1 } \\
\text { En baloncesto: el último segundo } \\
\text { y el balón alrededor del aro } \\
\text { Dolor del jugador que se lesiona } \\
\text { Veo el deporte como competición, } \\
\text { si no hay pasión no hay deporte }\end{array}$ & $\begin{array}{l}\text { Las lágrimas por la } 9^{\mathrm{a}} \text { del Real M. } \\
\text { Todo el mundo en los balcones por la } 9^{\mathrm{a}} \\
\text { Un loco apuñalando a M. Seles } \\
\text { Carlos Sáiz parado a un metro de la meta } \\
\text { Álvaro lesionado con la triada } \\
\text { Piloto estrellándose (A. Senna) } \\
\text { El último partido de Ferrero en Roland } \\
\text { G. } \\
\text { Fermín Cacho "entrando" en el estadio de } \\
\text { Monjuit } \\
\text { Las acrobacias del paracaidismo }\end{array}$ \\
\hline VALORES & $\begin{array}{l}\text { Chulería } \\
\text { Peleas } \\
\text { Un obstáculo: la pista de esquí } \\
\text { cuando dices ahí voy }\end{array}$ & $\begin{array}{l}\text { Alguien entrenando solo } \\
\text { Alguien sudoroso y cansado } \\
\text { con la cara "maachacao" bien. } \\
\text { con satisfacción } \\
\text { Perder una competición y ser } \\
\text { animado por un contrario } \\
\text { Competición y lucha }\end{array}$ & $\begin{array}{l}\text { Una gota de sudor que recorre la } \\
\text { piel } \\
\text { Para mi, sprint final, superación } \\
\text { Intercambio de camisetas } \\
\text { Un ciclista y su sufrimiento, } \\
\text { descolgado }\end{array}$ & $\begin{array}{l}\text { Los ultrasur gritando irrespetuosos y } \\
\text { pegando } \\
\text { Thyson cuando mordió la oreja } \\
\text { El escalador que se cortó la mano }\end{array}$ \\
\hline SOCIOECONÓMICOS & $\begin{array}{l}\text { Un campo de fútbol } \\
\text { Mucha gente } \\
\text { Marcas }\end{array}$ & $\begin{array}{l}\text { Un niño de } 10 \text { años con un } \\
\text { balón de } 10000 \text { pelas } \\
\text { Un niño con botas carísimas, } \\
\text { las de Ronaldo }\end{array}$ & Estadio en directo+ gritos & \\
\hline ICÓNICA-SIMBÓLICA & $\begin{array}{l}\text { Podio } \\
\text { Banderas } \\
\text { Movimiento } \\
\text { El colegio } \\
\text { Estadio Olímpico } \\
\text { Verano } \\
\text { La playita } \\
\text { Campo abierto con un río }\end{array}$ & $\begin{array}{l}\text { Nazi con la esvástica } \\
\text { aplaudiendo a un negro } \\
\text { Alguien que atraviesa paredes } \\
\text { o se quita cadenas (fuerza) } \\
\text { Gente boxeando rompiéndose } \\
\text { la cara haciendo deporte es } \\
\text { curioso (comiéndose la oreja) } \\
\text { Una grada tirando mecheros a } \\
\text { un jugador } \\
\text { Máquinas de engranajes que } \\
\text { se están engrasando } \\
\text { Un futbolista con un } \\
\text { Mercedes y la rubia al lado } \\
\text { Una abuelita colgándose de la } \\
\text { canasta }\end{array}$ & $\begin{array}{l}\text { La celebración en las fuentes } \\
\text { Himno de la Champions L. } \\
\text { Motociclistas en el podio con las } \\
\text { botellas de cava } \\
\text { El himno en el campo, la bandera } \\
\text { La cara pintada } \\
\text { Cara de un jugador después de } \\
\text { fallar un penalty }\end{array}$ & $\begin{array}{l}\text { La ola } \\
\text { El aire y la lluvia en la cara a toda } \\
\text { velocidad } \\
\text { F. Torres regateando a Hierro } \\
\text { La gente bañándose en una fuente } \\
\text { Típica imagen de tíos jugando al tenis, } \\
\text { lanzándose y haciendo volteretas } \\
\text { Las acrobacias del deporte de riesgo }\end{array}$ \\
\hline
\end{tabular}

Tabla 2. Metáforas del término deporte 


\subsection{Resultados particulares sobre los deportistas de elite}

Los sujetos de esta muestra, jóvenes deportistas becados y con domicilio en la residencia J. Blume, constituyen el segmento donde quizás más apasionadamente se vive el deporte, con sus grandezas y sus miserias, ya que son considerados potencial o actualmente como "deportistas de alto rendimiento".

Conocer sus opiniones acerca de los rasgos vinculados a nuestro objeto de estudio, su proyección futura, y otra información adicional que hemos recabado aprovechando la oportunidad privilegiada de tenerlos a nuestra disposición, satisface con creces los objetivos propios de esta investigación.

Los colectivos alcanzados en el presente Estudio, reflejan el siguiente perfil sociodemográfico:

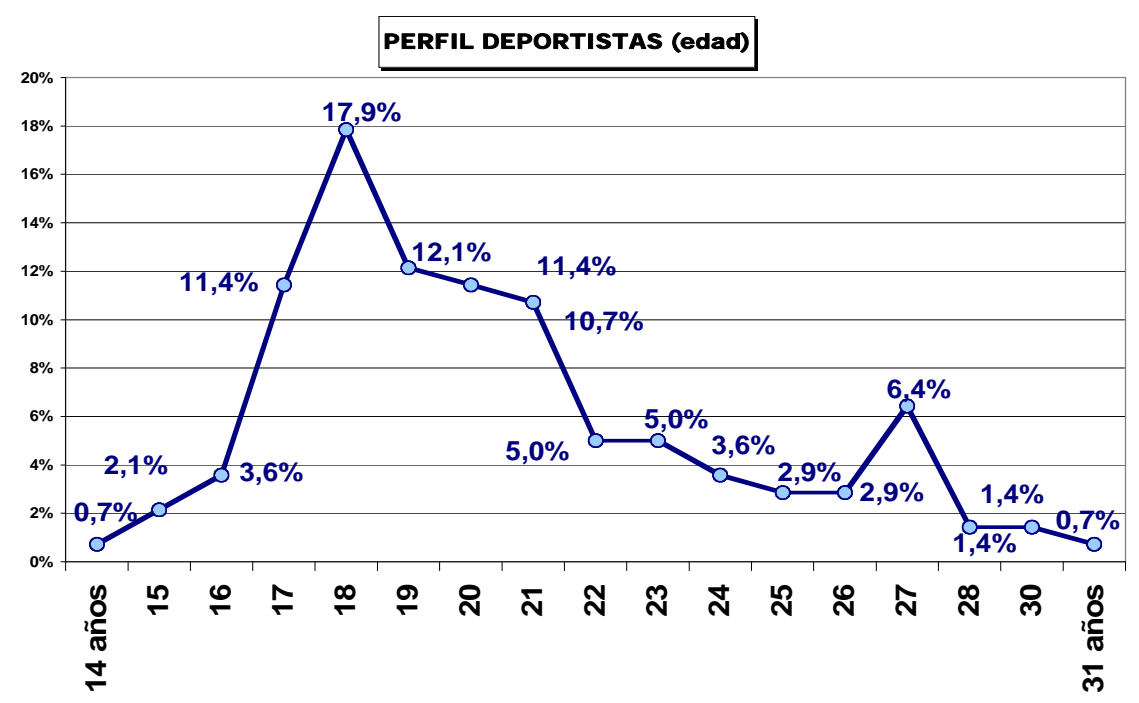

El segmento mayor en la muestra de deportistas se corresponde a los que tienen 18 años llegando a representar el 17,9\% del total.

Entre los 15 y 23 años se encuentra el grueso de la muestra, el 79,2\% del total, coincidiendo con lo que parece, en general, la etapa clave en la vida deportiva de elite. 
La representación por sexos está equilibrada dándose una buena distribución por edades, como se puede apreciar en el gráfico.

Según el estado civil, el 97,1\% corresponde a personas solteras.

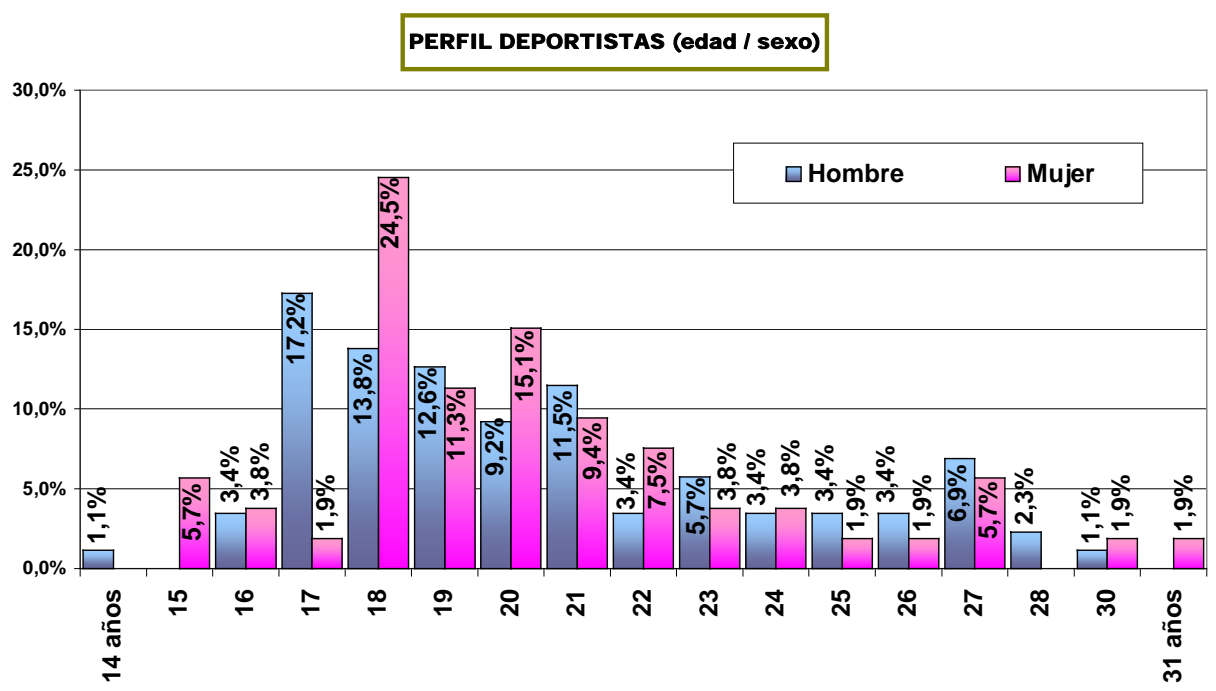

Realizando esta consulta en la Residencia J. Blume, hemos buscado deliberadamente los deportes y deportistas que menos atención reciben por parte de los medios de comunicación y con una actuación más individualizada.

El fútbol, baloncesto y balonmano, fundamentalmente deportes colectivos mucho más profesionalizados, podrían capitalizar los resultados característicos de esos deportes que representan la parte más visible, pero no la única del deporte. Tiene, básicamente, otros cauces de reclutamiento y desarrollo entre los jóvenes ligados a los clubes.

El grupo más numeroso, el 19,3\%, engloba las distintas disciplinas y pruebas de atletismo, seguido del hockey, $15 \%$, y piragüismo, $12,1 \%$. 


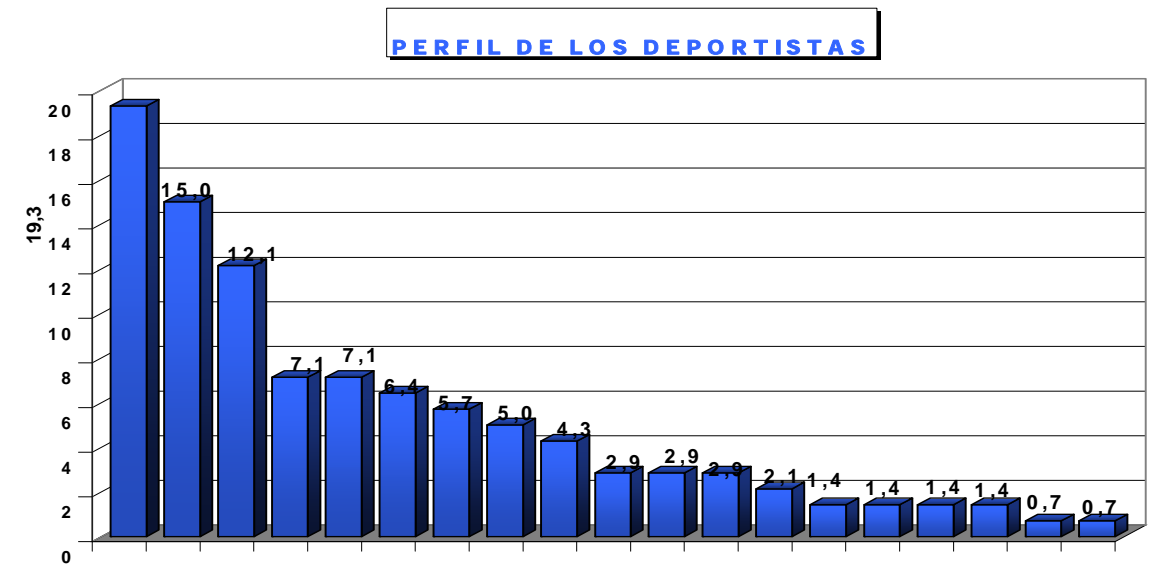

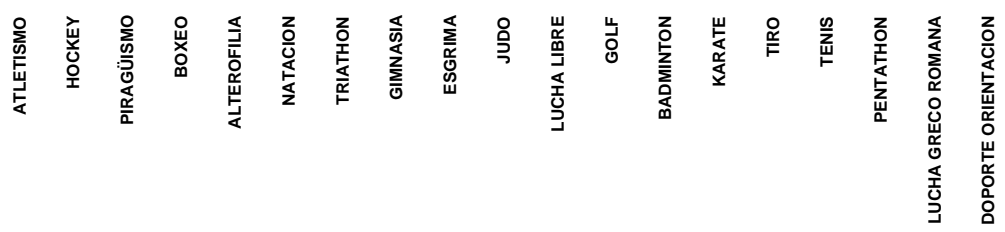

Ante el reto planteado de jerarquizar los rasgos del deporte como producto, tanto hombres y mujeres, valoran de forma similar las propuestas realizadas, por lo que ambos colectivos muestran las mismas inquietudes al respecto. Los aspectos salud, sistema de integración social, profesión y ocio, son los que destacan como más característicos.

Sólo se detecta una ligera diferencia en el rasgo juego, 0,6 puntos más en mujeres, y en el rasgo sistema social de integración, 0,5 puntos más en hombres. Para los hombres constituye más juego que para las mujeres y menos sistema social de integración.

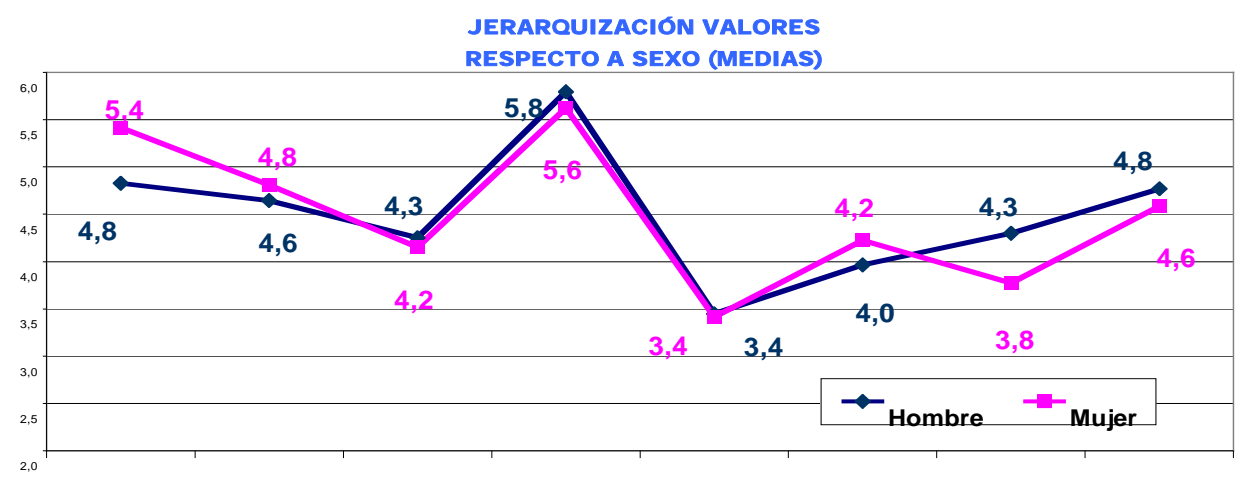

\begin{tabular}{|c|c|c|c|c|c|}
\hline 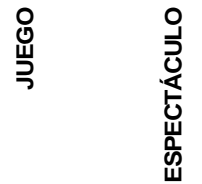 & $\frac{0}{8}$ & 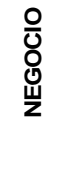 & 㭊 & $\begin{array}{l}z \\
\frac{z}{w} \\
\frac{u}{0} \\
\frac{\alpha}{a} \\
0\end{array}$ & 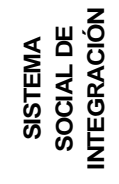 \\
\hline
\end{tabular}


Como se aprecia en todas las gráficas correspondientes a los grupos de edades, el rasgo que más se aleja de su consideración, o en otras palabras, con el que los deportistas no les gustaría que se relacionara el deporte, es Negocio. Sin embargo hay una plena coincidencia para relacionarlo con la salud.

Se aprecian ligeras tendencias de valoración de los factores propuestos entre los grupos de edad a los que pertenecen los deportistas.

Es curiosa la diferencia significativa que se aprecia en el rasgo ocio entre los más jóvenes $(3,7)$ y el grupo de mayor edad $(5,1)$, pudiendo deberse a que para estos últimos su actividad se ha convertido ya en una profesión y para los jóvenes es todavía una actividad relacionada con el tiempo libre (del colegio) y pasarlo bien. Si nos fijamos en otra diferencia entre los dos grupos relacionada con el rasgo negocio, puede confirmar esta apreciación significativa, los más jóvenes $(6,6)$ la puntuación más lejana de su concepto, los más mayores $(5,3)$ la más cercana de los cuatro grupos de edad.

JERARQUIZAR LOS SIGUIENTES VALORES (MEDIAS)

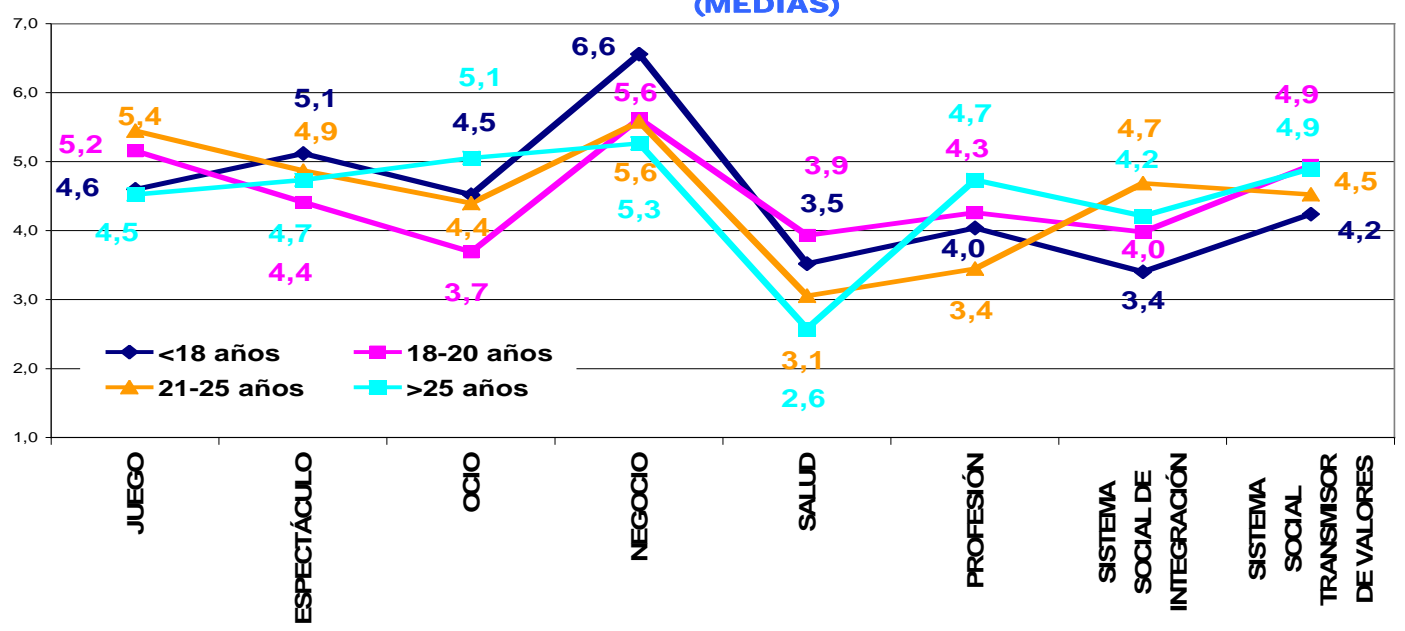




\subsection{Resultados particulares sobre los docentes del deporte}

Los sujetos de la muestra de este segmento, educadores relacionados con diversos aspectos del deporte, tienen un protagonismo capital en la conformación de la personalidad de los educandos en el contexto social de la formación.

Tener en cuenta sus opiniones respecto a un amplio abanico de cuestiones esenciales de nuestro objeto de estudio, es una exigencia que no podíamos pasar por alto en el conjunto de nuestra investigación.

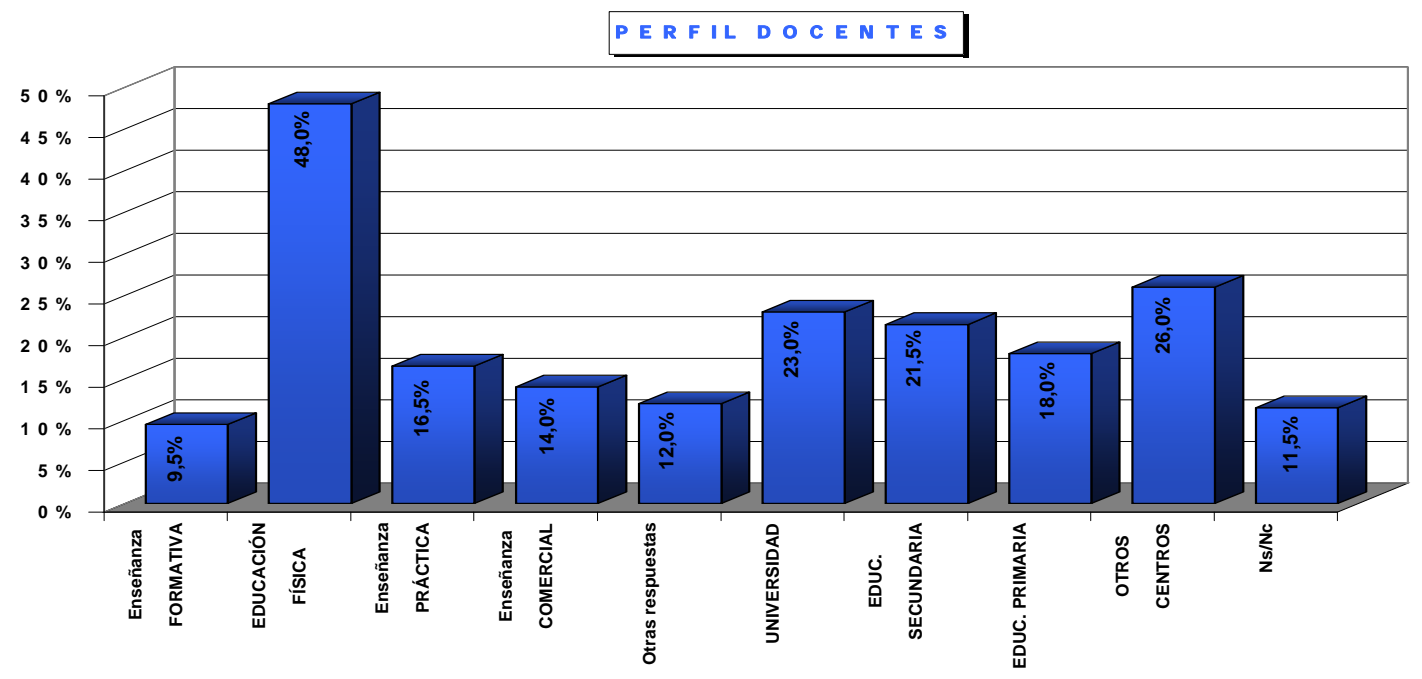

Como se puede apreciar en el gráfico anterior, los profesores de educación física constituyen el segmento más numeroso $(48 \%)$ de la muestra, no podía ser de otra manera cuando estamos tratando el deporte.

En relación al tipo de enseñanza, primaria, secundaria, universitaria y otros centros (probablemente clubes y asociaciones), se constata una representación equilibrada.

En la variable centros de enseñanza, un $11,5 \%$ de docentes ha respondido Ns-Nc, y hemos creído conveniente prescindir de ellos a la hora de realizar las gráficas para 
tener una mejor visión de los resultados, aunque los valores medios y porcentajes están calculados con ellos incluidos.

Según la variable sexo, hay una representación mayor de hombres $(69,0 \%)$ que de mujeres $(31,0 \%)$, que refleja la situación real del ámbito que representa la muestra.

En relación a la edad, hemos establecido tres rangos, menos de 30 años $(40,0 \%)$, $31-45$ años $(40,5 \%)$ y más de 45 años $(19,5 \%)$.

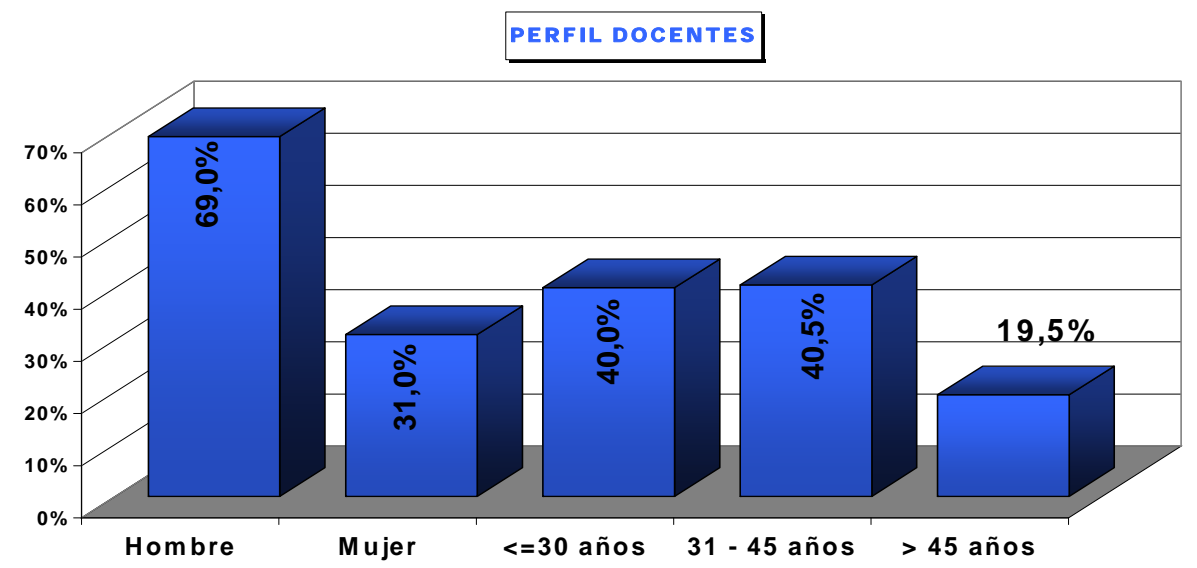

Planteada la cuestión, la salud $(4,8)$ y el ocio $(4,7)$ son los rasgos a los que, en valores medios, otorgan más importancia los docentes.

Negocio $(6,0)$ es el rasgo que para los encuestados menor simpatía despierta como factor asociado al deporte. 


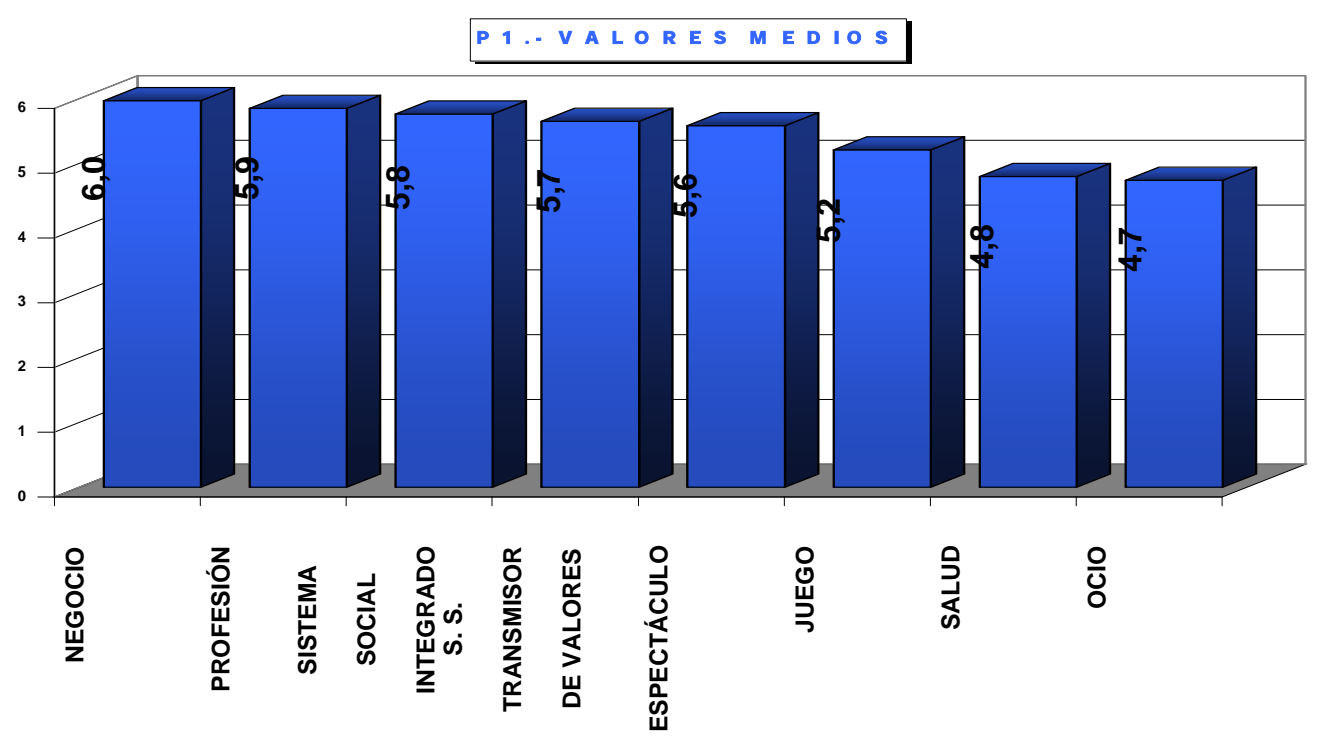

Para los docentes de educación secundaria, el deporte como negocio $(5,6)$ y el deporte como juego $(3,5)$ son los dos rasgos que se encuentran en los polos opuestos y que tienen que estar lo más separado posible dentro del entorno deportivo.

Los docentes agrupados en "otros centros" se desmarcan del resto en "ocio" $(3,1)$ y "salud" $(3,5)$ otorgándoles el primer puesto y el segundo como más característicos del deporte.

Los docentes universitarios se comportan de una forma más homogénea, no destacando ningún atributo de forma contundente del resto a excepción del factor salud $(3,7)$. 

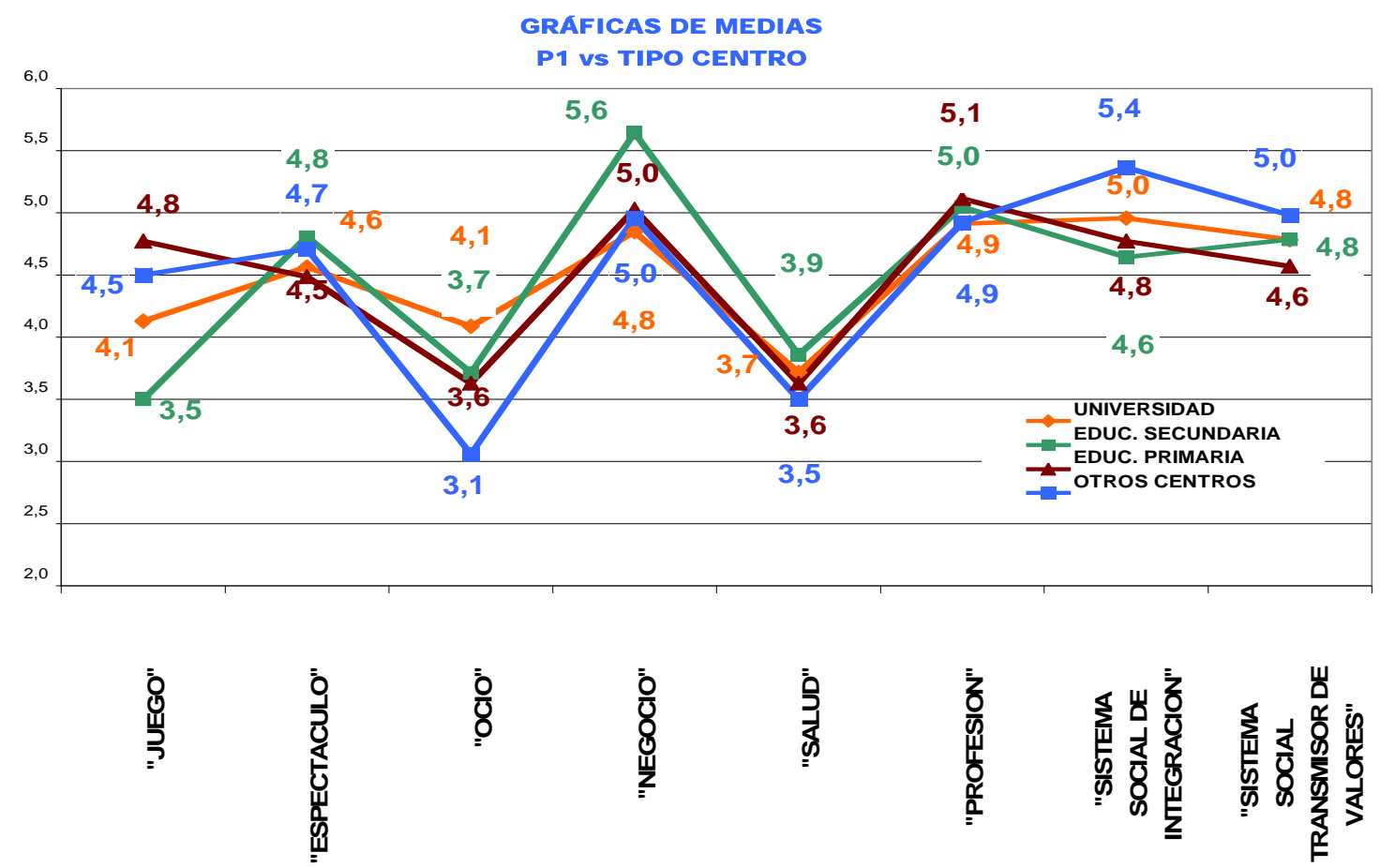

El deporte, en su conjunto como producto, es visto principalmente como ocio y salud, siendo estos los rasgos más valorados por los docentes, exceptuando a los pertenecientes a "otras enseñanzas" para quienes el negocio $(3,4)$ y el espectáculo $(3,4)$ son los factores más característicos en contraste con el resto de docentes. No es de extrañar puesto que "otras enseñanzas" recogen las opiniones de entrenadores y monitores más enfocados al deporte de competición.

A la hora de buscar diferencias podemos decir que la opinión que expresan los docentes difiere dependiendo del centro en el que imparten enseñanza.

En el punto donde están todos más de acuerdo es en lo referido al deporte visto como una profesión.

Hay que destacar que los docentes pertenecientes a otras enseñanzas opinan que el negocio y el espectáculo son los dos rasgos que predominan en la actualidad en el deporte visto como producto en contraste con el resto de docentes. 


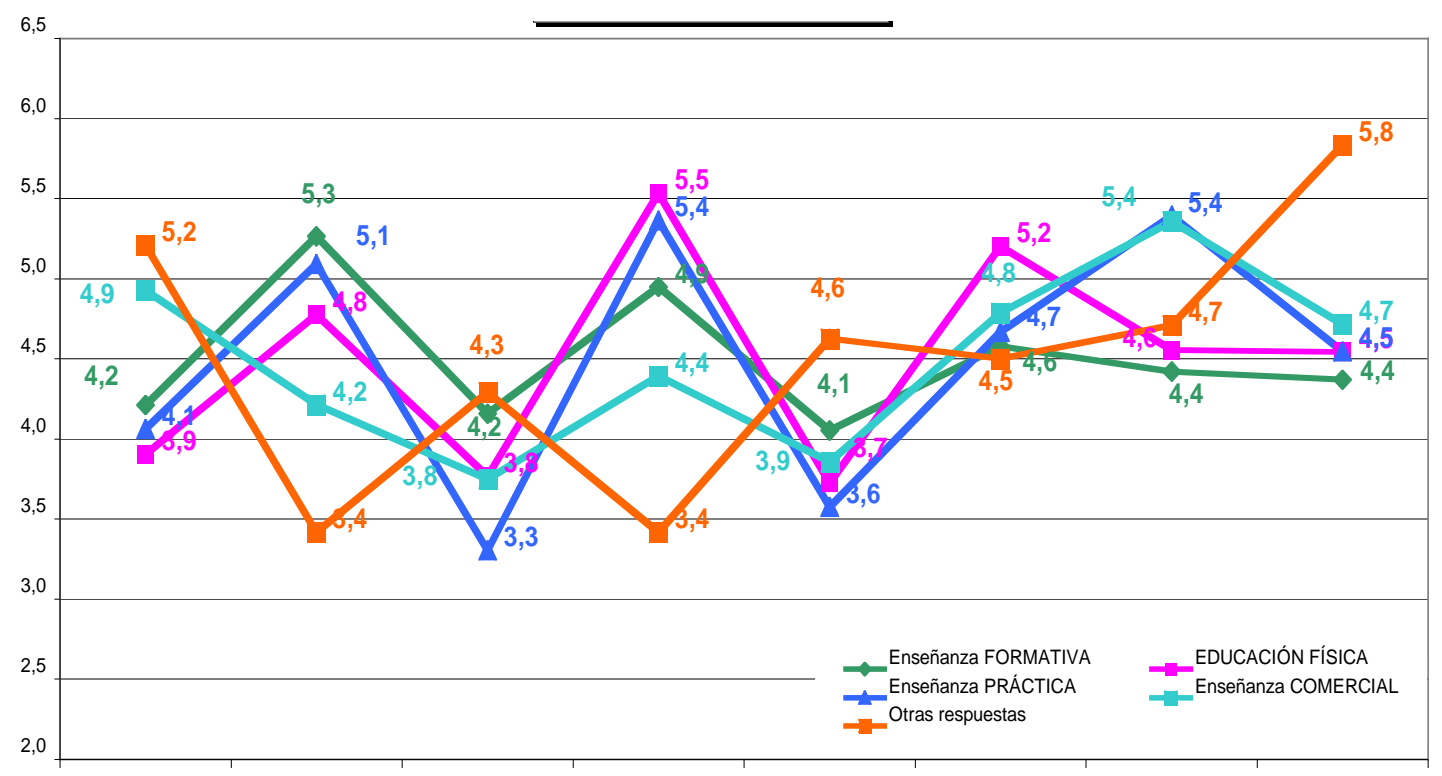

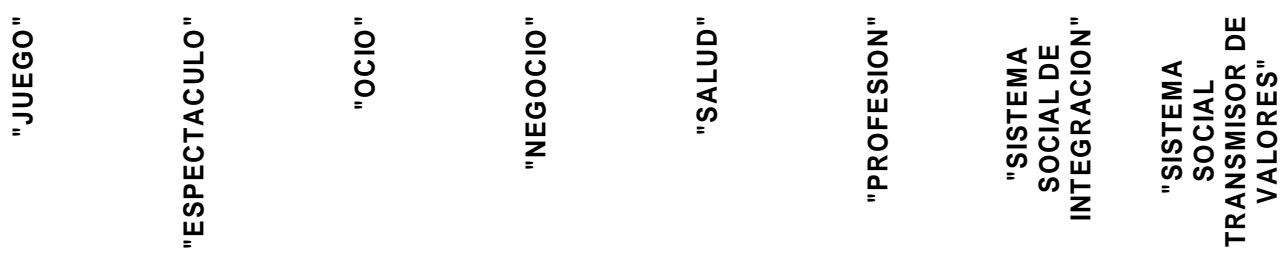

No se observan diferencias significativas según la variable sexo, aunque se aprecia una mayor idealización por parte de las mujeres en torno a las variables socialmente más valoradas.

Las mujeres caracterizan al deporte como una institución que puede servir de mediador sistema social de integración $(4,4)$ la mayor distancia entre hombres y mujeres, una herramienta para el entretenimiento y ocio $(3,7)$ y como factor de salud $(3,9)$. 


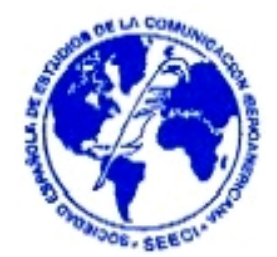

RASGOS VINCULADOS AL

DEPORTE RESPECTO AL SEXO

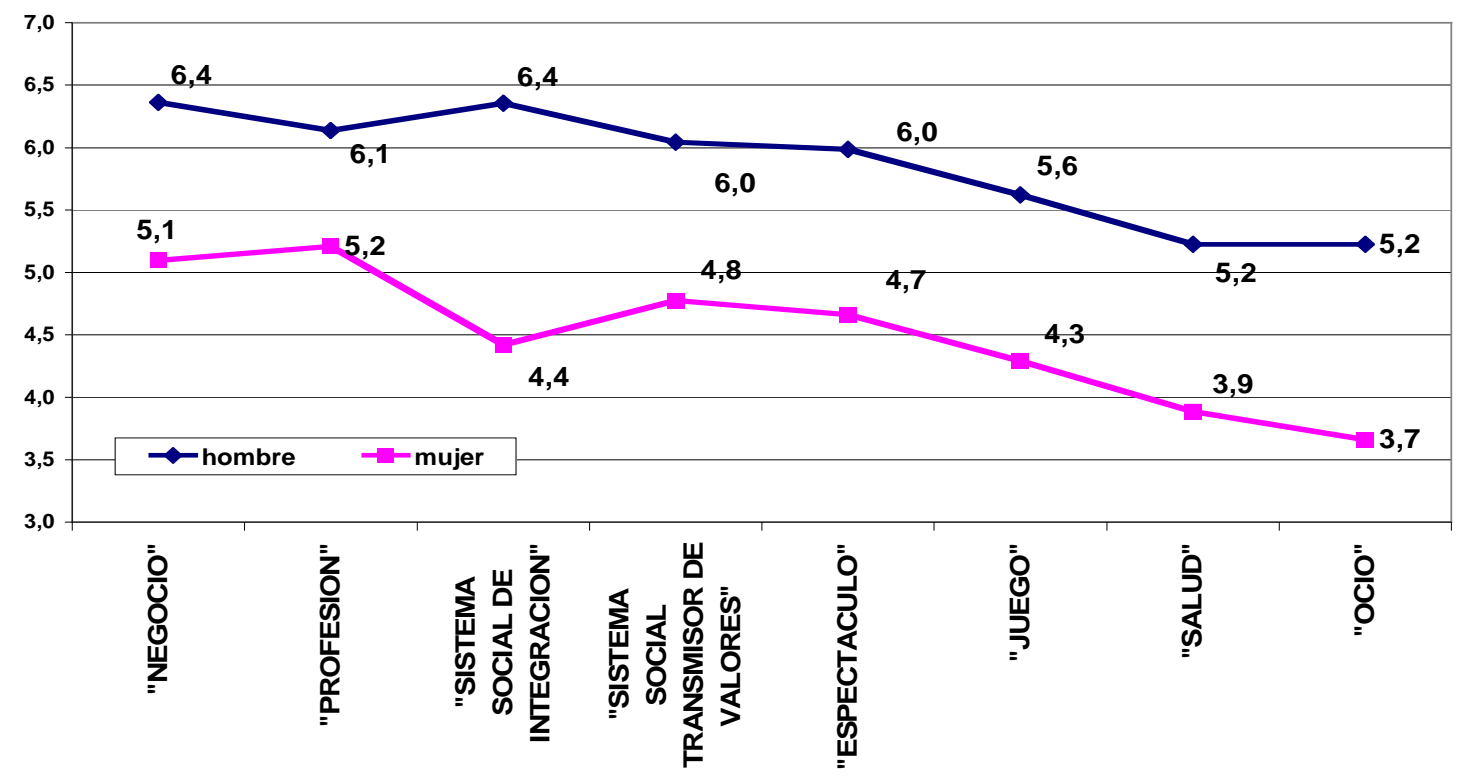

En cuanto a la variable edad, a la hora de jerarquizar los rasgos definidos en el estudio encontramos diferencias entre el grupo < 30 años y el grupo de 31-45 años, destacando que salud $(3,4)$ y ocio $(3,6)$ son los rasgos mejor valorados por todos y más en concreto por los docentes comprendidos entre 31 - 45 años.

VALORES VINCULADOS AL DEPORTE

( respecto edad)

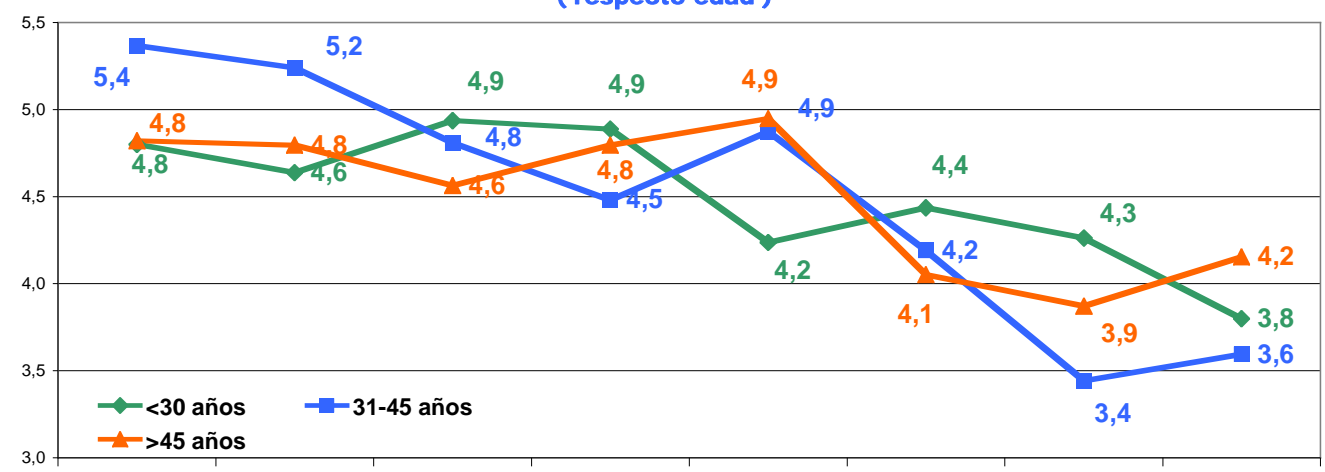

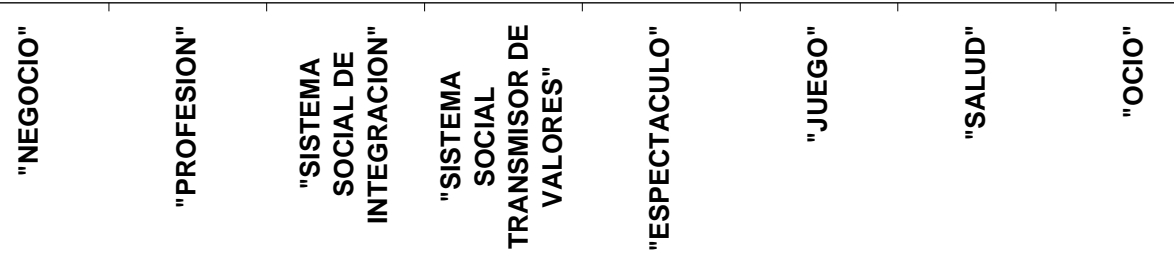




\subsection{Resultados particulares sobre los líderes de opinión (expertos)}

Ante el interrogante que nos planteamos acerca de los aspectos que engloba el deporte como producto susceptible de intercambio, en el momento actual, se observa que de forma generalizada hay una clara bipolaridad en el concepto deporte. Esto nos lleva a una primera diferenciación: la práctica del deporte (amateur) y deporte profesional.

El primero, deporte amateur aglutina una serie de valores intrínsecos con la misma práctica de la actividad que representan:

- Aspecto psicosocial de integración, componente formativo de cooperación, de participación, de integración, eliminación de desigualdad social, diversión en grupo por el componente lúdico social tanto activa como pasiva.

- Aspecto individual formativo: se induce al compromiso, la superación, obtener el triunfo, competitividad de superación, hábitos de vida, esfuerzo, sacrificio, diversión individual activa y pasiva.

- Aspecto salud: Hábitos de vida sana por el beneficio claro de la actividad sobre la salud, beneficios en la calidad de vida, estética. Sanidad recomienda la práctica deportiva como "remedio" a diversas dolencias.

- Aspecto lúdico /entretenimiento, como canalizador y catalizador en la vida tanto de los que lo practican como de los espectadores (activo y pasivo).

El segundo, deporte profesional comparte algunos de los aspectos del deporte amateur, y posee además otros importantes, que lo diferencian del anterior: 
"El deporte profesional configura un sistema lleno de contradicciones en el que las líneas entre los valores positivos y los valores negativos son extremadamente finas y fácilmente traspasables"

- Aspecto psicosocial de integración donde prevalece más el papel espectador que el participativo, de integración.

- Aspecto individual formativo, compromiso, superación, competitividad de superación, hábitos de vida, esfuerzo, sacrificio, todo esto lo encontramos en la práctica dinámica de la actividad, no así en la pasiva, donde prevalece el espectáculo.

- Aspecto salud: hábitos de vida sana por los beneficios que pueda acarrear a la salud, a través de la imitación de los deportistas líderes. Dentro del deporte profesional aparece un aspecto conflictivo en lo relativo a la salud, el uso de estimulantes que puede representar un modelo social poco recomendable. Esto está totalmente relacionado con el aspecto mercantilista/ negocio del deporte.

- Aspecto mercantilista/ negocio : este componente del deporte profesional afecta a los propios deportistas, las entidades deportivas (clubes, asociaciones, etc.), medios de difusión, empresas patrocinadoras y a los propios espectadores.

Es un fenómeno que se retroalimenta a sí mismo, en la medida que se difunde más, atrae a más espectadores y es en definitiva un "fenómeno de marketing".

Conlleva en ocasiones una desigualdad de oportunidades entre los Clubes más poderosos y otros más desfavorecidos.

"Para el Real Madrid el mercado será el mundo, para el Recreativo de Huelva el mercado será Huelva" 
Desigualdad de oportunidades entre los deportistas.

En ocasiones este aspecto mercantilista puede perjudicar a la actividad misma y a los espectadores que pueden ver limitado su acceso al disfrute del deporte.

- Aspecto aspiracional, como medio de alcanzar un estatus superior, un modo de vida bien remunerado. Los deportistas famosos se transforman en símbolos de referencia para los jóvenes.

- Aspecto político, en ocasiones el deporte se transforma en instrumento político utilizado por regímenes de todo tipo.

- Aspecto lúdico/ entretenimiento en el caso del deporte profesional, prima más el espectáculo, como espectáculo es más pasivo que activo. Es un fenómeno claro de grandes masas.

\section{Conclusiones}

Nuestra primera conclusión, como se evidencia contundentemente en todos los grupos de sujetos, es que el deporte integra un numeroso conjunto de factores relacionados que lo definen como objeto (no físico) de consumo en la actualidad. Es practicado como sana diversión o profesionalmente; es disfrutado como espectáculo ante el televisor $\mathrm{o}$ acudiendo al evento $\mathrm{y}$ adquiriendo merchandising $\mathrm{u}$ otros productos relacionados; es vivido apasionadamente cuando se interioriza.

- Los jóvenes manifiestan lo que el deporte es para ellos alrededor de cinco aristas: educativa, salud, económica, social, cultural y lúdica. Y distinguen dos ámbitos claramente separados: 
1. Profesional: espectáculo, negocio, emoción, competitividad, agresividad, fanatismo, odio, actividad física, racismo, compañerismo, ayuda, apoyo, y trabajo en equipo.

2. Práctica lúdica: satisfacción, esfuerzo, superación personal, diversión, amistad, salud, y relaciones sociales.

En ambas esferas, cuando el deportes está interiorizado, la pasión es el sentimiento dominante.

- Los deportistas de elite jerarquizan los rasgos que caracterizan su concepto del deporte: salud, profesión, sistema de integración social, ocio, éxito social y económico, manifestando su aversión al factor negocio, y otorgándole una escasa importancia como sistema social de transmisión de valores.

- Los rasgos más valorados por los docentes son: ocio, salud, juego, espectáculo, sistema transmisor de valores; el que más se aleja de su concepto es el factor negocio. Para ellos, los sectores que más importancia tienen, por el papel que desempeñan en la actualidad, son: el deporte espectáculo y el deporte profesional, los medios de comunicación (especializados), los fabricantes de bienes deportivos, el sector salud y el deporte como ocio.

- Los expertos establecen una clara diferenciación entre deporte profesional y la práctica deportiva, reconociéndole aspectos propios de sus componentes: psicosocial de integración, individual formativo, salud, lúdico/entretenimiento, mercantilista/negocio, político y aspiraciones.

- El deporte también presenta atributos negativos: el doping, fanatismo, rivalidad extrema, violencia, y entorno machista. 
Estos mismos resultados evidencian otra diáfana conclusión: la esencia del deporte es tridimensional, ya que se trata de un "todo" que participa de la esencia de un bien material, de una idea y se concreta fundamentalmente como servicio como se ilustra en la figura 1.

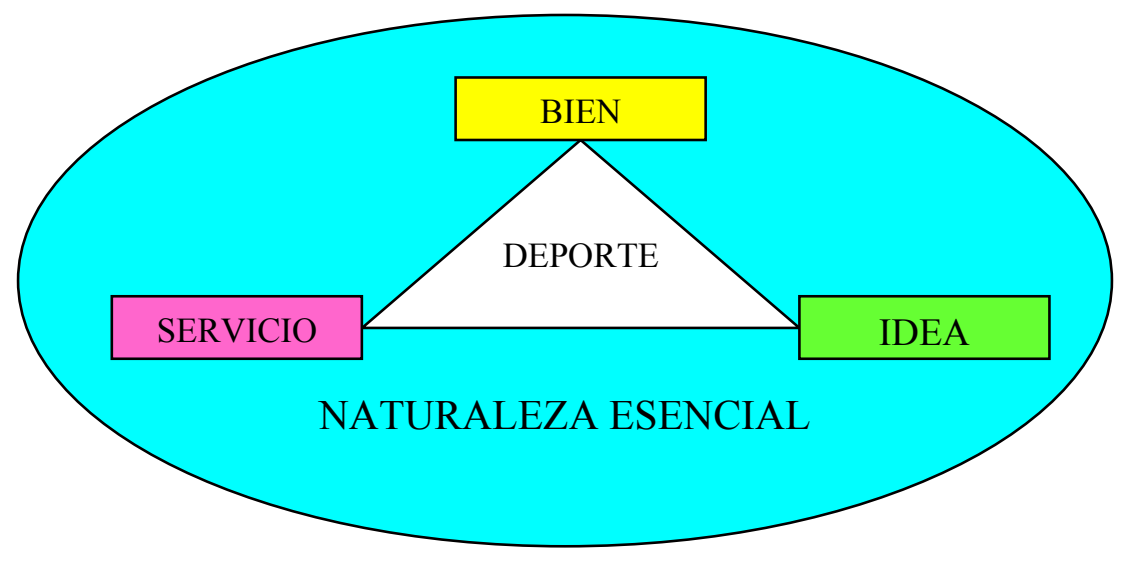

Figura 1. Naturaleza esencial del producto deporte (Elaboración propia).

Tal como presenta la figura 2. Productos y servicios del sistema deportivo, hemos recogido todos los componentes de lo que consideramos constituye el producto deporte, en la seguridad de que el sistema deportivo propicia la relación de todos ellos para configurar un concepto esencialmente tridimensional y único desde el punto de vista del marketing. 
REVISTA DE LA SEECI.

Ramírez Perdiguero, Francisco Javier (2009): Redefinición del concepto deporte como producto de intercambio. No 20. Noviembre. Año XIII. Páginas: 1-39

ISSN: 1576-3420 DOI: http://dx.doi.org/10.15198/seeci.2009.20.1-39

\section{MARCA / IDENTIDAD CORPORATIVA}

$$
\begin{aligned}
& \text { - Espectáculo en vivo } \\
&- \text { Estadio } \\
&- \text { TV } \\
&- \text { Radio } \\
&- \text { Internet }
\end{aligned}
$$

- Diarios y revistas

- Archivos digitales

- Estadísticas, canales de noticias

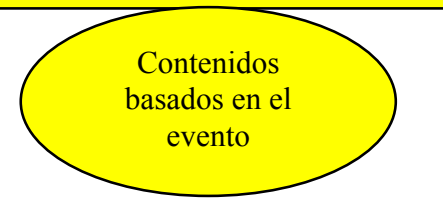

- Espectáculo en vivo

- $\quad$ Estadio

- TV

- Radio

Internet

- Diarios y revistas

- Archivos digitales

- Estadísticas, canales de noticias

- Historia del equipo

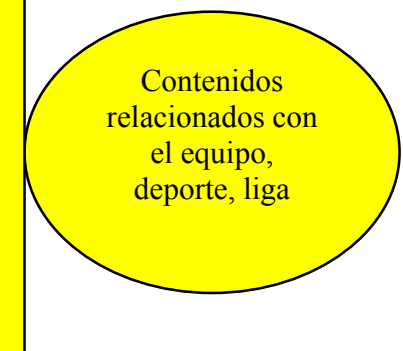

\section{- Turismo deportivo \\ - Ligas fantásticas \\ - Apuestas \\ deportivas on- $y$ \\ offline}
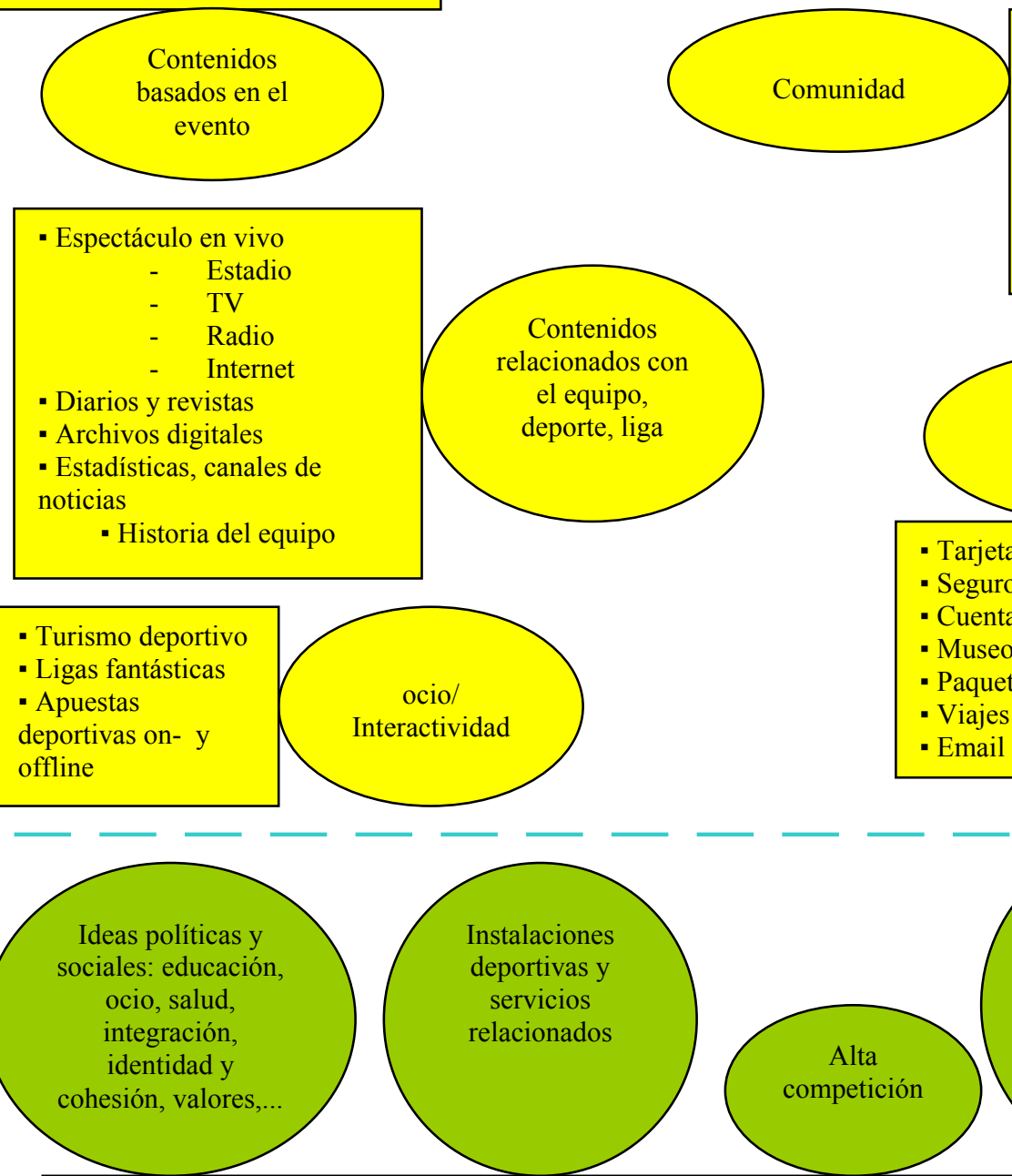

- Estadio (Evento del descanso y otros entretenimientos, Palcos VIP)

- Internet, incluyendo tablón de anuncios y chats

- Merchandising del deporte, liga,...

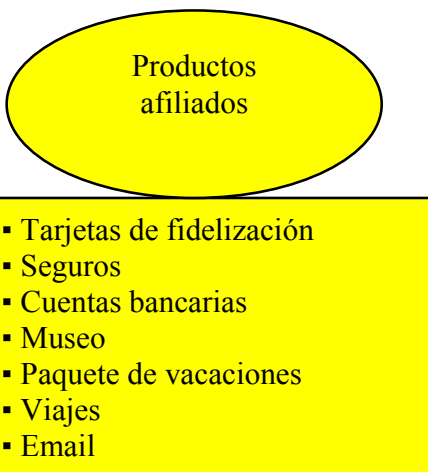

- Tarjetas de fidelizació

Seguros

- Paquete de vacaciones

Formación: entrenadores y técnicos.

Programas: niños, servicios relacionados

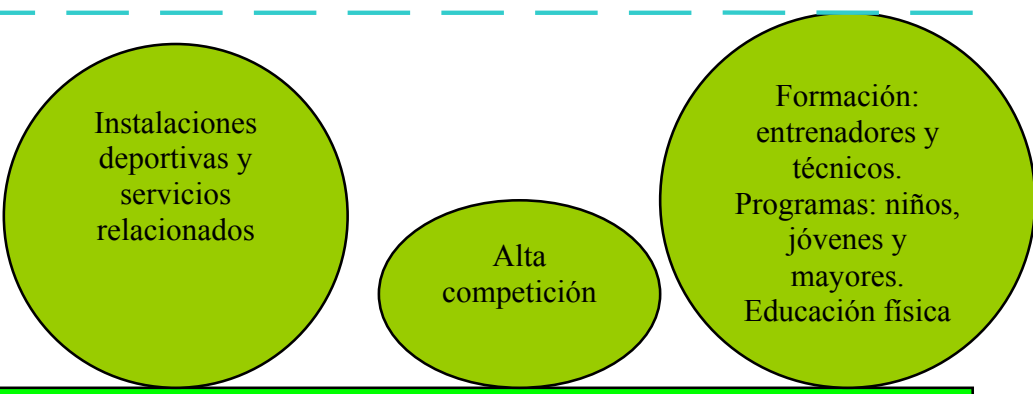

Ideas y Servicios para la práctica masiva del deporte

NUEVAS TECNOLOGÍAS

- Interactividad (telefonía móvil, animación 3D, MSM,...)

- Internet

- TV Digital

Figura 2. Adaptado de A.T.Kearney ( 2003) Productos y servicios del ecosistema del deporte 
En el área amarilla, están recogidos los producto relativos al deporte profesional y que son más visibles a través de los medios de comunicación, pero no los más importantes, como demuestra Gratton (2002) y otros autores, amparados por un factor determinante como es la marca, como parte fundamental de la identidad corporativa.. El área verde corresponde a los productos relacionados con la práctica masiva del deporte cuya importancia, además del volumen económico de difícil cálculo que representa, radica en las funciones en las que la Unión Europea insiste frecuentemente:

1. Una función educativa: la actividad deportiva constituye un excelente instrumento para equilibrar la formación y el desarrollo humano de la persona, cualquiera que sea su edad;

2. Una función de salud pública: la actividad física ofrece la ocasión de mejorar la salud de los ciudadanos y de luchar de forma eficaz contra algunas enfermedades, como las lesiones cardíacas o el cáncer; y puede contribuir al mantenimiento de una buena salud y calidad de vida a una edad avanzada;

3. Una función social: el deporte representa un instrumento adecuado para promover una sociedad más inclusiva y para luchar contra la intolerancia, el racismo, la violencia, el abuso de alcohol o el uso de estupefacientes; el deporte puede contribuir a la integración de las personas excluidas del mercado de trabajo;

4. Una función cultural: la práctica deportiva permite al ciudadano enraizarse en mayor medida en un territorio, conocerlo mejor e integrarse mejor en él y, en lo referente al medio ambiente, protegerlo mejor;

5. Una función lúdica: la práctica deportiva es un componente importante del tiempo libre y de la diversión individual y colectiva.

Queremos destacar también, con el área gris, que las nuevas tecnologías ya han provocado la aparición de nuevos productos deportivos/comunicativos, sobre todo en el ámbito profesional, pero lo más importante creemos que está por llegar. 


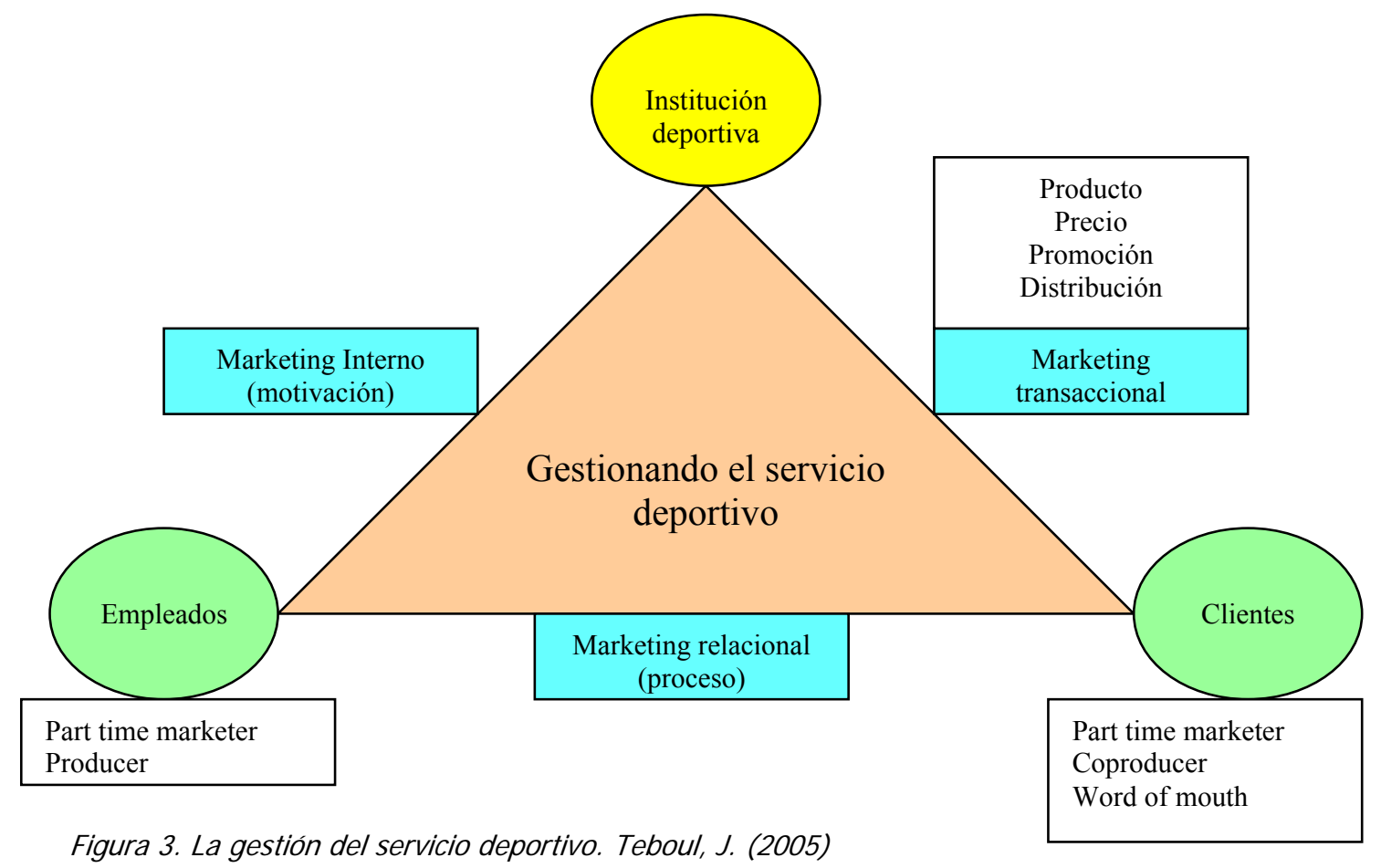

Por último, para completar nuestra aportación, es imprescindible afirmar que la forma más frecuente que el tipo de oferta que adopta el producto deporte es como servicio.

La figura 3. La gestión del servicio deportivo, muestra los tres elementos que intervienen en la producción del deporte y su relación en el escenario (front stage) y entre bastidores (back stage). Se establece lo que denomina Teboul (2005) una cultura dual empresarial (dual partnership culture) donde los empleados y los clientes están al mismo nivel, y donde el proceso es tan importante como el contenido. 
Ramírez Perdiguero, Francisco Javier (2009): Redefinición del concepto deporte como producto de intercambio. No 20. Noviembre. Año XIII. Páginas: 1-39 ISSN: 1576-3420 DOI: http://dx.doi.org/10.15198/seeci.2009.20.1-3

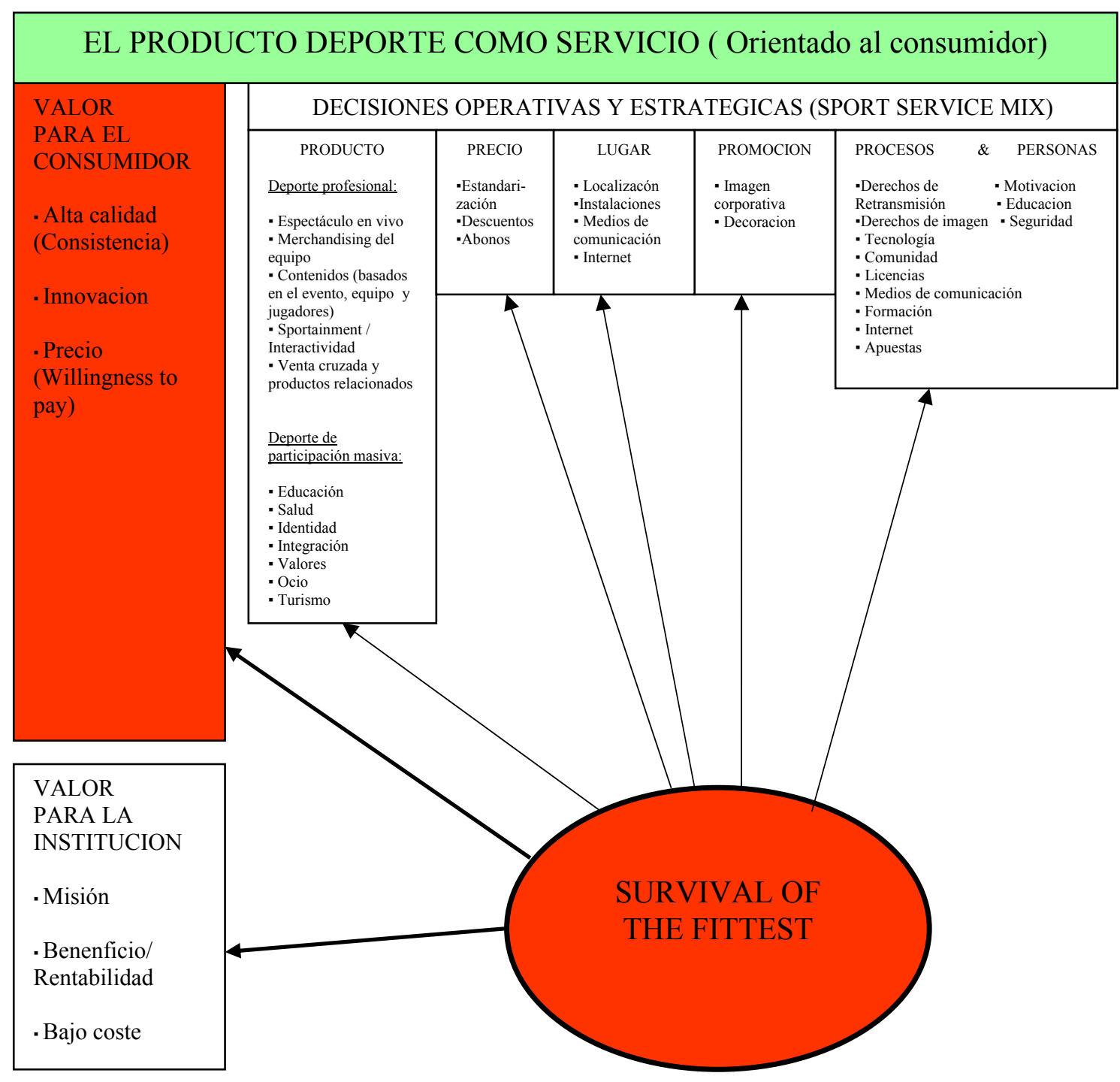

Figura 4. Success of a sport service (product). Adapted from Teboul (2005)

La gestión de un servicio deportivo es más compleja que la de un bien puro. En un servicio siempre hay dos partes, escenario (Frontstage) y bastidores (Backstage), que hay que poner en juego y que pueden crear conflictos, sobre todo en el deporte profesional y vital para los intereses de los medios de comunicación. El servicio se materializa en el "escenario" y se produce entre "bastidores". 
El servicio hay que hacerlo tangible, haciéndolo memorable y mostrando el valor para el cliente. Hemos de ser muy persuasivos en el escenario y ofrecer la máxima calidad. Mientras, entre bastidores, debemos ser muy flexibles con las necesidades gustos y preferencias del clientes, tratar de estandarizar la producción del servicio y reducir costes al máximo. Un buen servicio es aquél que ajusta perfectamente el valor para el cliente (value to customer), el valor para la institución (value to company)y las decisiones en el service mix (operations and decisions).

El mix de un servicio deportivo (sport service mix) implica la gestión de seis elementos: producto, precio, promoción, distribución, proceso y personas (estos dos últimos son inseparables).

En este contexto es donde se general el valor para el cliente y el valor para la institución, tomando las decisiones operativas oportunas en el service mix, tal como recoge la figura 4.

De esta manera queda configurado nuestra redefinición del producto deporte, que estamos convencidos irá evolucionando más en la dirección que condicionen las necesidades, gustos y preferencias de los consumidores, que en la voluntad de los responsables de marketing. Éstos deben estar atentos a los indicios que se presenten para crear nuevas formas de satisfacer las demandas de los consumidores. 


\section{Bibliografía}

KEARNEY, A. T. (2003). El nuevo consumidor del deporte. Marketing and Communication. A.T. Kearney. Chicago.

KEARNEY, A. T. (2003). Que los juegos comiencen. Encarando los temas y retos en la nueva industria del deporte. Marketing and Communication. A.T. Kearney. Chicago.

AGUDO, A. y TOYOS, F. (2003). Marketing del Fútbol. Pirámide. Madrid.

AMBlER, T. (2000). Marketing y Beneficios. Prentice Hall. Madrid.

BALBONI, A. (1994). "A new management for a new concept of sport" en 20 Congress of the European Association for Sport Management. Florence. Italy.Blanc (1999)

BROWN W., Helen. (1999). "The Psychology of Relationship Marketing and Public Leisure Provision In the UK - Serving the Person or Meeting Customer Needs?" en 7th Congress of the European Association for Sport Management. Tsalónica (Grecia).

BRUNELLI, M. y SEMPRINI, M. (2000). The Internet and professional football: an European perspective. European Journal for Sport Management

BRUNELLI M., PIANI P. y TACCONI G. (1999). The Marketing Function of Italian and English Football Clubs. 7th Congress of the European Association for Sport Management- Thessaloniki. Greece.

BURNETT, J., MENON, A. y SMART, D. (1993). Sports Marketing: A new ball game with new rules. Journal of Advertising Research, 33. Septiembre/Octubre. New York. 
BURTON, R., QUESTER, P.G.. y FARRELL, F. J. (1998). “Organizational Power Games" en Revista Marketing Management, 7. Estados Unidos.

CAMPOS LÓPEZ, C. (1997). Marketing y patrocinio deportivo. Gestió i Promoció Editorial S.A. Barcelona.

CAMPOS LÓPEZ, C. (1996). Gestión Deportiva. Tesis Doctoral. Departamento de Economía de la Empresa. Universidad de Cádiz.

Consejo Superior de Deportes (2002). Prevención del dopaje en el ámbito educativo. CSD. Madrid

FELD, CH. (2005). Liderazgo de IT en 2010. Internacional Programme. INSEAD. Fointainbleu.

GRATTON, C. (2002). Previsiones sobre el gasto del los consumidores en deporte. Jornadas Internacionales sobre economía y deporte: aspectos socioeconómicos del deporte. Instituto Andaluz del Deporte. Málaga.

GRATTON, C. (2002). "The Future of Sport Economics" en 10th. European Sport Management Congress. Jyväskylä. Finlandia.

HERMOSO DE MENDOZA, C. (2001). Deporte con estrategia. I pMark 558/16

KOTLER, PH.; CÁMARA, D.; GRANDE, I. y CRUZ, I. (2000). Dirección de marketing. Edición del Milenio. Prentice Hall. Pearson Education, S.A. Madrid.

KOTHLER, PH. y TRIAS DE BES, F. (2004). Marketing Lateral. Pearson Educación. Madrid. 
MILLMAN, J. (1999). "The shots heard round the business world" en Revista Brandweek no 40. Estados Unidos.

MILNE, G. y MCDONALD, M. (1998). Sport Marketing. Managing the exchange process. Jones and Bartlett Publishers. London.

MORENO, I. (2002). Musas y nuevas tecnologías. Piados Comunicación. Barcelona.

MORENO, I.. (2003). Narrativa audiovisual publitaria. Editorial Piados. Barcelona.

MULLIN, B. J., HARDY, S. y SUTTON, W. A. (1999). Marketing deportivo. Editorial Paidotribo. Barcelona.

OLCESE, A. (2005). Responsabilidad corporativa. Programa Internacional de Desarrollo Directivo. Universidad Francisco de Vitoria. Madrid.

PAREDES ORTIZ, J. (2002). El deporte como juego: un análisis cultural. Tesis Doctoral. Biblioteca Virtual Miguel de Cervantes.

PICARD, R. y KLEIN, J. (2002). "Computers that recognize and respond to user emotion: theoretical and practical implications" en Interacting with Computers no 14

PITTS, B. y STOTLAR, D. (2002). Fundamentals of Sport Marketing. Fitness Information Technology, Inc. Morgantown, W.V.

RAMÍREZ PERDIGUERO, F.J. (2005). Marketing y deporte: El producto deporte en el mercado global y su relación de intercambio en Internet. Tesis doctoral. Universidad Complutense. Madrid. 
SALVADOR, J.L. (2004). El Deporte en Occidente. Historia, cultura y política. Cátedra. Madrid.

SANTESMASES, M. (2001). Marketing, conceptos y estrategias. Pirámide. Madrid.

SCHMITT, B.H. (2000). Experiential Marketing. Ediciones Deusto. Bilbao.

SHILBURY, D., QUICK, S., y WESTERBEEK, H. M. (1998). Strategic Sport Marketing. Allen \& Unwin. St Leonards, NSW.

SMITH, A. y WESBERBEEK, H. (2004). The Sport Business Future. Palgrave Macmillan. New York.

SMOLIANOV, P. (1999). A management and evaluation model for sport marketing campaigns. 7th Congress of the European Association for Sport Management. Thessaloniki. Greece.

TEBOUL, J. (2005). Specificity of Services. International challenges programme. INSEAD. Fontainbleu. No publicado.

WESTERBEEK, H. y SMITH, A. (2003). Sport business in the global marketplace. Palgrave Macmillan. New York.

WORLDWATCH INSTITUTE. (2004). La Situación del Mundo. Icaria Editorial. Barcelona. 